\title{
Distinct Nrf2 Signaling Mechanisms of Fumaric Acid Esters and Their Role in Neuroprotection against 1-Methyl-4- Phenyl-1,2,3,6-Tetrahydropyridine-Induced Experimental Parkinson's-Like Disease
}

\begin{abstract}
${ }^{\circ}$ Manuj Ahuja, ${ }^{1 \star}$ Navneet Ammal Kaidery, ${ }^{1 \star}$ Lichuan Yang, ${ }^{1,7,12}$ Noel Calingasan, ${ }^{7}$ Natalya Smirnova, ${ }^{8,9}$ Arsen Gaisin, ${ }^{10}$ Irina N. Gaisina, ${ }^{11}$ Irina Gazaryan, ${ }^{8,13}$ Dmitry M. Hushpulian, ${ }^{14,15}$ Ismail Kaddour-Djebbar, ${ }^{3,6}$ Wendy B. Bollag, ${ }^{3,4,5,6}$ John C. Morgan, ${ }^{2,6}{ }^{\circ}$ Rajiv R. Ratan, ${ }^{8}{ }^{\circledR}$ Anatoly A. Starkov, ${ }^{7}$ M. Flint Beal, 7 and Bobby Thomas ${ }^{1,2}$

Departments of ${ }^{1}$ harmacology and Toxicology, ${ }^{2}$ Neurology, ${ }^{3}$ Physiology, ${ }^{4}$ Oral Biology, and ${ }^{5}$ Medicine, Medical College of Georgia, Augusta University, Augusta, Georgia 30912, ${ }^{6}$ Charlie Norwood Veterans Affairs Medical Center, Augusta, Georgia 30912, ${ }^{7}$ Brain and Mind Research Institute Weill Cornell Medicine, Cornell University, New York, New York 10065, ${ }^{8}$ Burke Cornell Medical Center, White Plains, New York 10605, ${ }^{9}$ D. Rogachev Federal Scientific and Clinical Center for Pediatric Hematology, Oncology, and Immunology, 117997 Moscow, Russia, ${ }^{10} \mathrm{Center}$ for Molecular Innovation and Drug Discovery, Northwestern University, Evanston, Illinois 60208, ${ }^{11}$ College of Pharmacy, University of Illinois, Illinois, Chicago 60612, ${ }^{12}$ Kunming Biomed International, Yunnan, China 650500, ${ }^{13}$ Department of Chemistry and Physical Sciences, Pace University, Pleasantville, New York 10570, ${ }^{14}$ Department of Chemistry, Moscow State University, 119991 Moscow, Russia, and ${ }^{15}$ Valenta Pharm, 119530 Moscow, Russia
\end{abstract}

A promising approach to neurotherapeutics involves activating the nuclear-factor-E2-related factor 2 (Nrf2)/antioxidant response element signaling, which regulates expression of antioxidant, anti-inflammatory, and cytoprotective genes. Tecfidera, a putative Nrf2 activator, is an oral formulation of dimethylfumarate (DMF) used to treat multiple sclerosis. We compared the effects of DMF and its bioactive metabolite monomethylfumarate (MMF) on Nrf2 signaling and their ability to block 1-methyl-4-phenyl-1,2,3,6tetrahydropyridine (MPTP)-induced experimental Parkinson's disease (PD). We show that in vitro DMF and MMF activate the Nrf2 pathway via S-alkylation of the Nrf2 inhibitor Keap1 and by causing nuclear exit of the Nrf2 repressor Bach1. Nrf2 activation by DMF but not MMF was associated with depletion of glutathione, decreased cell viability, and inhibition of mitochondrial oxygen consumption and glycolysis rates in a dose-dependent manner, whereas MMF increased these activities in vitro. However, both DMF and MMF upregulated mitochondrial biogenesis in vitro in an Nrf2-dependent manner. Despite the in vitro differences, both DMF and MMF exerted similar neuroprotective effects and blocked MPTP neurotoxicity in wild-type but not in Nrf2 null mice. Our data suggest that DMF and MMF exhibit neuroprotective effects against MPTP neurotoxicity because of their distinct Nrf2-mediated antioxidant, anti-inflammatory, and mitochondrial functional/biogenetic effects, but MMF does so without depleting glutathione and inhibiting mitochondrial and glycolytic functions. Given that oxidative damage, neuroinflammation, and mitochondrial dysfunction are all implicated in PD pathogenesis, our results provide preclinical evidence for the development of MMF rather than DMF as a novel PD therapeutic.

Key words: fumarates; inflammation; mitochondria; MPTP; Nrf2; oxidative stress

\section{Significance Statement}

Almost two centuries since its first description by James Parkinson, Parkinson's disease (PD) remains an incurable disease with limited symptomatic treatment. The current study provides preclinical evidence that a Food and Drug Administration-approved drug, dimethylfumarate (DMF), and its metabolite monomethylfumarate (MMF) can block nigrostriatal dopaminergic neurodegeneration in a 1-methyl-4-phenyl-1,2,3,6-tetrahydropyridine mouse model of PD. We elucidated mechanisms by which DMF and its active metabolite MMF activates the redox-sensitive transcription factor nuclear-factor-E2-related factor 2 (Nrf2) to upregulate antioxidant, anti-inflammatory, mitochondrial biosynthetic and cytoprotective genes to render neuroprotection via distinct S-alkylating properties and depletion of glutathione. Our data suggest that targeting Nrf2-mediated gene transcription using MMF rather than DMF is a promising approach to block oxidative stress, neuroinflammation, and mitochondrial dysfunction for therapeutic intervention in PD while minimizing side effects. 


\section{Introduction}

Parkinson's disease (PD) is a progressively debilitating neurodegenerative movement disorder characterized by a profound loss of midbrain dopaminergic neurons in the substantia nigra pars compacta $(\mathrm{SNpc})$. Despite intensive research, the current treatment options rely heavily on dopamine (DA) replacement therapies and are inadequate to slow or stop the degenerative process (Savitt et al., 2006). Although the cause of PD is unknown, data from sporadic and genetic forms of PD support a role for oxidative stress, neuroinflammation, and mitochondrial dysfunction in disease pathogenesis. An emerging target for PD that could modulate multiple etiological pathways involves drug-induced activation of a coordinated antioxidant genetic program to maintain redox equilibrium by means of expression of prosurvival proteins and cytoprotective genes (Calkins et al., 2009). A key transcription factor orchestrating this process is nuclear factor erythroid 2-related factor 2 (Nrf2), a member of the cap'n' collar family of basic leucine zipper transcription factors. In addition to its role in protection from oxidative stress, Nrf2 triggers expression of growth factors and genes responsible for drug detoxification, immunomodulation, intracellular signaling, and cellular bioenergetics (Calabrese et al., 2010; Dinkova-Kostova et al., 2015). The breadth of this endogenous response suggests that its activation might counterbalance many of the large number of etiological pathways implicated in PD pathogenesis.

Numerous proof-of-principle studies involving gain and loss of function of Nrf2 in the brain have suggested that its induction can ameliorate neurodegeneration, whereas its deficiency exacerbates neurodegenerative phenotypes (Zhang et al., 2013). Tecfidera is a Food and Drug Administration-approved oral formulation of dimethylfumarate (DMF) for multiple sclerosis (MS; Fox et al., 2012; Gold et al., 2012). DMF is highly active in combating oxidative stress and inflammation by activating the Nrf2 genetic program to promote axonal regeneration and neurological recovery in MS and in many preclinical models of neurodegenerative diseases (Ellrichmann et al., 2011; Linker et al., 2011; Iniaghe et al., 2015; Jing et al., 2015; Liu et al., 2015), making DMF a promising therapeutic drug. Here, we compared Nrf2-dependent neuroprotective mechanisms of DMF and its bioactive metabolite monomethylfumarate (MMF) against 1-methyl-4-phenyl-1,2,3,6-tetrahydropyridine (MPTP)induced experimental PD. We show that DMF reacted spontaneously with thiols via a Michael-type addition to form adducts with a resultant reduction in glutathione (GSH), activating the Nrf2 pathway by depleting cellular levels of GSH and reducing cell viability in a dose-dependent manner. Conversely, MMF had a very low reactivity toward GSH and did not affect GSH levels and cell viability. The extent of S-alkylation induced by DMF and

Received Feb. 3, 2016; revised April 19, 2016; accepted May 2, 2016.

Author contributions: A.G., I.N.G., I.G., and B.T. designed research; M.A., N.A.K., L.Y., N.C., N.S., A.G., I.N.G., D.M.H., I.K.-D., and A.S. performed research; W.B.B., J.C.M., R.R.R., and M.F.B. contributed unpublished reagents/analytic tools; M.A., N.A.K., L.Y., N.C., N.S., A.G., I.N.G., I.G., A.S., and B.T. analyzed data; A.S. and B.T. wrote the paper.

This work is supported in part by National Institutes of Health Grants NS062165 and NS060885 (B.T.) and AG014930 (A.A.S), the Michael J. Fox Foundation for Parkinson's Disease (B.T.), the National Parkinson Foundation CSRA Chapter (B.T.), Par fore Parkinson (B.T.), Veterans Affairs Research Career Scientist Award (W.B.B.). N.A.K. is a Parkinson Disease Foundation postdoctoral fellow. We thank Dr. Terrance Kavanagh (University of Washington, Seattle, WA) for GCLC and GCLM antibodies, Dr. Curt Freed (University of Colorado, Denver, C0) for rat dopaminergic 1RB3AN27 (N27) cells, and Dr. Masayuki Yamamoto (Tohoku University, Sendai, Japan) for Nrf2 knock-out mice.

${ }^{*}$ M.A. and N.A.K. contributed equally to this work.

The authors declare no competing financial interests.

Correspondence should be addressed to Dr. Bobby Thomas, Departments of Pharmacology and Toxicology, and Neurology, Medical College of Georgia, Augusta University, Augusta, GA 30912. E-mail: bthomas1@augusta.edu. DOI:10.1523/JNEUROSCI.0426-16.2016

Copyright $\odot 2016$ the authors $\quad 0270-6474 / 16 / 366333-20 \$ 15.00 / 0$
MMF was directly proportional to their ability to activate the Nrf2 pathway in vitro, with DMF acting as a stronger Nrf2 activator than MMF and is associated with nuclear exit of the Nrf2 repressor Bach1. Activation of Nrf2 by DMF, but not MMF, was associated with inhibition of the mitochondrial oxygen consumption rate (OCR) and glycolysis in a dose-dependent manner, whereas MMF increased these activities. Moreover, DMF and MMF upregulated genes involved in mitochondrial biogenesis in wild-type but not Nrf2 null mouse embryonic fibroblasts (MEFs). Despite these in vitro differences of their modes of action, oral administration of both DMF and MMF attenuated MPTP neurotoxicity with similar potency in the wild-type but not Nrf2 null mice, which was accompanied by blockade of MPTP-induced oxidative damage and neuroinflammation. Our results suggest that DMF and MMF protect against MPTP neurotoxicity because of their distinct Nrf2-dependent activation of antioxidative, anti-inflammatory, and cytoprotective genes, including those involved in mitochondrial biogenesis, but MMF does so without depleting GSH or inhibiting mitochondrial and glycolytic functions, which can lead to cell death. These results provide preclinical evidence for the development of MMF rather than DMF as a novel PD therapeutic.

\section{Materials and Methods}

Animals and chemicals. Two different strains of mice C57BL/6 and Nrf2 knock-out $(\mathrm{KO})$ mice were used in the present study. C57BL/6 mice (https://www.jax.org/strain/000664; The Jackson Laboratory) and Nrf2KO mice (Itoh et al., 1997; Dr. Masayuki Yamamoto, Tohoku University, Sendai, Japan) used in the present study were on a pure C57BL/6 background (Kaidery et al., 2013). Age-matched wild-type and Nrf2-KO male mice used in the present study were obtained by crossing Nrf2 heterozygous mice in the institutional animal care facility. Mice were housed in a pathogen-free facility and exposed to a $12 \mathrm{~h} \mathrm{light/dark} \mathrm{cycle} \mathrm{with} \mathrm{food}$ and water provided ad libitum. Mice were maintained and treated strictly according to National Institutes of Health Guidelines for the Care and Use of Laboratory Animals. The Institutional Animal Care and Use Committees of Augusta University (Augusta, GA) and Weill Cornell Medicine (New York, NY) approved all procedures. All the chemicals used in the study were procured from Sigma-Aldrich unless stated otherwise.

Cell culture studies. Rat N27 dopaminergic cells were maintained in RPMI 1640 medium (Thermo Fisher Scientific) supplemented with glutamine, $10 \%$ FBS, $100 \mathrm{U} / \mathrm{ml}$ penicillin, and $100 \mu \mathrm{g} / \mathrm{ml}$ streptomycin at $37^{\circ} \mathrm{C}$ in a humidified atmosphere of $5 \% \mathrm{CO}_{2}$. Cells were cultured to $80 \%$ confluence in six-well plates, treated with the respective concentrations of DMF and MMF for the times indicated in the figure legends, and harvested for real-time PCR and immunoblotting. For cell viability studies, cells were plated in 96-well plates with 5000 cells per well. After overnight incubation, cells were treated with DMF, MMF, 1-methyl-4phenyl-pyridinium ion $\left(\mathrm{MPP}^{+}\right)$, or MPP ${ }^{+}$in combination with DMF or $\mathrm{MMF}$ and zinc protoporphyrin [ZnPP; inhibitor of hemeoxygenase 1 (Hmox-1)] at the indicated doses and time points, and cytotoxicity was assessed by Presto-Blue cell proliferation assays (Thermo Fisher Scientific). Human M17 neuroblastoma cells were maintained in OPTI-MEM media containing $0.5 \%$ FBS, $100 \mathrm{U} / \mathrm{ml}$ penicillin, and $100 \mu \mathrm{g} / \mathrm{ml}$ streptomycin at $37^{\circ} \mathrm{C}$ in a humidified atmosphere of $5 \% \mathrm{CO}_{2}$. M17 cells were cultured to $80 \%$ confluence in $100 \mathrm{~mm}$ dishes and treated with the respective concentrations of DMF and MMF for the time points indicated. The NE-PER Nuclear and Cytosolic extraction kit (Thermo Fisher Scientific) was used to fractionate nuclear and cytosolic fractions according to the instructions of the manufacturer. Wild-type and Nrf2-KO MEFs were maintained in Iscove's modified Dulbecco's medium supplemented with $10 \% \mathrm{FBS}, 100 \mathrm{U} / \mathrm{ml}$ penicillin, and $100 \mu \mathrm{g} / \mathrm{ml}$ streptomycin, in a humidified incubator set at $37^{\circ} \mathrm{C}$ and $5 \% \mathrm{CO}_{2}$. For real-time PCR and immunoblotting, cells were cultured to $80 \%$ confluence in six-well plates and treated with the respective concentrations of DMF and MMF for the times indicated. Human neuroblastoma SH-SY5Y cells stably expressing Neh2-luc and ODD-luc reporters were grown in the DMEM/F-12 sup- 
Table 1. List of primers used for the study

\begin{tabular}{|c|c|c|c|c|c|}
\hline Species & Gene identifier & Gene name & GenBank accession number & Forward primer sequence & Reverse primer sequence \\
\hline Mouse & Hmox1 & Heme oxygenase 1 & NM_010442.2 & GTCAAGCACAGGGTGACAGA & ATCACCTGCAGCTCCTCAAA \\
\hline Mouse & Nq01 & NAD(P)H dehydrogenase, quinone 1 & NM_008706.5 & AGCGTTCGGTATTACGATCC & AGTACAATCAGGGCTCTTCTCG \\
\hline Mouse & Gclc & Glutamate-cysteine ligase, catalytic subunit & NM_010295.1 & ATGATAGAACACGGGAGGAGAG & TGATCCTAAAGCGATTGTTCTTC \\
\hline Mouse & Gsr & Glutathione reductase & NM_010344.4 & AGTTCCTCACGAGAGCCAGA & CAGCTGAAAGAAGCCATCACT \\
\hline Mouse & $C d 68$ & Cd68 antigen & NM_001291058.1 & GACCTACATCAGAGCCCGAGT & CGCCATGAATGTCCACTG \\
\hline Mouse & Mcp1 & Monocyte chemoattractant protein-1 & NM_011333.3 & CATCCACGTGTTGGCTCA & GATCATCTTGCTGGTGAATGAGT \\
\hline Mouse & $m t-N d 1$ & Mitochondrial NADH dehydrogenase subunit 1 & ENSMUSG000000664341 & GCACCTACCCTATCACTCACA & GTTTGGGCTACGGCTCG \\
\hline Mouse & $m t-N d 2$ & Mitochondrial NADH dehydrogenase subunit 2 & ENSMUSG00000064345 & AGGGATCCCACTGCACATAG & TGAGGGATGGGTTGTAAGGA \\
\hline Mouse & $m t-N d 5$ & Mitochondrial NADH dehydrogenase subunit 5 & ENSMUSG00000064367 & ATAACCGCATCGGAGACATC & GAGGCCAAATTGTGCTGATT \\
\hline Mouse & $m t-N d 6$ & Mitochondrial NADH dehydrogenase subunit 6 & ENSMUSG000000664368 & ATGTTGGAAGGAGGGATTGGG & TACCCGCAAACAAAGATCACC \\
\hline Mouse & Ssbp1 & Single-stranded DNA binding protein 1, mitochondrial & NM_212468.3 & GTCGGGCTCTGCGTGTC & ACCAAACTGCTGGCTACTTCA \\
\hline Mouse & Mterf1a & Mitochondrial transcription termination factor 1a & NM_001013023.2 & GTCCAGAGGCGGAAGTGAAA & AATCATCAGGTAGCCCAAAGTT \\
\hline Mouse & Polg2 & Polymerase (DNA directed), $\gamma 2$, accessory subunit & NM_015810.2 & TGGCTTGATTTCTGGTTGCG & CGCTGCTGAAGTTAGAGGGA \\
\hline Mouse & Peo1 (Twinkle) & Progressive external ophthalmoplegia 1 & NM_153796.3 & GACAGCATCCATTTTCGGCTC & GCCCAGTCACCAGTTTCCTATC \\
\hline Mouse & $m t-C y t b$ & Mitochondrial cytochrome $b$ & ENSMUSG00000064370.1 & ATTCCTTCATGTCGGACGAG & ACTGAGAAGCCCCCTCAAAT \\
\hline Mouse & $m t-C 03$ & Mitochondrial cytochrome c oxidase subunit III & ENSMUSG00000064358.1 & CAAGGCCACCACACTCCTAT & ATTCCTGTTGGAGGTCAGCA \\
\hline Mouse & Tfam & Transcription factor A, mitochondrial & NM_009360.4 & TCCCCTCGTCTATCAGTCTTGT & TCTTTGTATGCTTTCCACTCAGC \\
\hline Mouse & Gapdh & Glyceraldehyde-3-phosphate dehydrogenase & NM_008084.2 & GCCAAAAGGGTCATCATCTC & САCACCCATCACAAACATGG \\
\hline Mouse & Actb & Actin, $\beta$ & NM_007393.3 & CTAAGGCCAACCGTGAAAAG & ACCAGAGGCATACAGGGACA \\
\hline Rat & Hmox1 & Heme oxygenase 1 & NM_012580.2 & GTCAAGCACAGGGTGACAGA & CTGCAGCTCCTCAAACAGC \\
\hline Rat & Nq01 & NAD(P)H dehydrogenase, quinone 1 & NM_017000.3 & AGCGCTTGACACTACGATCC & CAATCAGGGCTCTTCTCACC \\
\hline Rat & Gclc & Glutamate-cysteine ligase, catalytic subunit & NM_017305.2 & CTGACTCACAATGACCCAAAAG & TTCAATGTCAGGGATGCTTTC \\
\hline Rat & Gclm & Glutamate-cysteine ligase, modifier subunit & NM_012815.2 & GGCGATGTTCTTGAAACTCTG & CAGAGGGTTGGGTGGTTG \\
\hline Rat & Gsr & Glutathione reductase & NM_053906.2 & ATCAAGGAGAAGCGGGATGC & AATGTTGCGTAGCCGTGGAT \\
\hline
\end{tabular}

plemented with GlutaMAX (Thermo Fisher Scientific) containing 10\% FBS, $100 \mathrm{U} / \mathrm{ml}$ penicillin, and $100 \mu \mathrm{g} / \mathrm{ml}$ streptomycin.

Luciferase reporter assays. SH-SY5Y cells expressing the Neh2-luc reporter were used to measure Nrf2 activation by DMF and MMF using a previously described method (Kaidery et al., 2013). In brief, DMF, MMF, and tert-butylhydroquinone (TBHQ) were tested in 96-well format white, flat-bottom plates at different concentrations $(0.05-80 \mu \mathrm{M})$. Neh2-luc reporter cells were plated at a density of 25,000 cells per well using a WellMate multichannel dispenser from Matrix (Thermo Fisher Scientific) and grown overnight on DMEM/F-12 plus GlutaMAX (100 $\mu \mathrm{l} /$ well). The drugs ( $2 \mu \mathrm{l}$ of $50 \times$ stock solutions in DMSO prepared in a master plate, right before use) and DMSO in control groups were added, and the plates were incubated for $3 \mathrm{~h}$; the medium was removed, cells were lysed, and luciferase activity was measured on a SpectraMax M5 ${ }^{\mathrm{e}}$ Microplate Reader with BrightGlo reagent (Promega). The reporter activation was normalized to the background luminescence. The effect of reducing agents $(5 \mu \mathrm{l}$ of $20 \times$ stock solution in PBS added to each well, 0.5 mu final concentration) was studied during simultaneous addition with the activator. The experiments were performed in triplicate. To demonstrate selectivity of Nrf2 activation, hypoxia-inducible factor-1 (HIF-1) ODD-luc reporter assay with SH-SY5Y/HIF-1 ODD-luc was performed in the presence of DMF and MMF as described previously (Kaidery et al., 2013). Ciclopirox and dimethyloxallyl glycine (DMOG) were used as positive controls (Kaidery et al., 2013).

RNA isolation and real-time RT-PCR. Total RNA from N27 cells, wildtype and Nrf2-KO MEFs, mouse liver, and ventral midbrain was isolated using TRIzol reagent according to the protocol of the manufacturer (Thermo Fisher Scientific). Reverse transcription of $\sim 2 \mu \mathrm{g}$ of total RNA was performed using a High-Capacity cDNA Reverse Transcription kit (Thermo Fisher Scientific). The cDNA was diluted, and $\sim 20$ ng was used to amplify in an ABI prism 7900 HT Real-time PCR system (Applied
Biosystems) for various genes using primers (Table 1) and Fast SYBR Green Master Mix (Thermo Fisher Scientific) in a $10 \mu \mathrm{l}$ reaction mixture. Cycling parameters were $95^{\circ} \mathrm{C}$ for $10 \mathrm{~s}$, followed by $60^{\circ} \mathrm{C}$ for $1 \mathrm{~min}$. Relative expression was calculated using the $\Delta \Delta \mathrm{Ct}$ method (Livak and Schmittgen, 2001). Values are expressed as a fold change from control reaction and normalized to glyceraldehyde-3-phosphate dehydrogenase (GAPDH) or $\beta$-actin expression.

Western blot analysis. Total protein extracts from N27 rat dopaminergic cells and M17 human neuroblastoma cells were prepared by homogenization in TNE buffer [10 mm Tris-HCl, pH 7.4, $150 \mathrm{~mm} \mathrm{NaCl,} 5$ mM EDTA, $0.5 \%$ NP-40, $1 \times$ Complete protease inhibitor cocktail (Roche), and $1 \times$ phosphatase inhibitor cocktail I and II (Sigma)]. Protein concentrations from total, cytosolic, and nuclear fractions were determined by the BCA method (Thermo Fisher Scientific), and 20-40 $\mu \mathrm{g}$ of protein was resolved by SDS-PAGE, transferred to nitrocellulose, and probed using appropriate primary antibodies anti-Nrf2 (1:2000, Epitomics for M17 cells), anti-Nrf2 (1:2000, C-20; Santa Cruz Biotechnology for N27 cells), anti-NADPH quinone oxidoreductase 1 (NQO1; 1:1000; Abcam), anti-glutathione reductase (GSR; 1:2000; Abcam), anti-glutamate-cysteine catalytic subunit (GCLC; 1:10,000), anti-glutamate-cysteine modifier subunit (GCLM; 1:10,000), anti-Hmox-1 (1:2500; Abcam), anti-Bach1 (1:1000; Santa Cruz Biotechnology), anti-poly(ADP-ribose) polymerase 1 (PARP1; 1:1000; Santa Cruz Biotechnology), anti-aldolasel (1:2000; Abcam), $\beta$-actin (1:1000; Abcam), and anti-GAPDH (1:5000; Fitzgerald). Western blotting analysis of the relative levels of the five oxidative phosphorylation (OXPHOS) complexes in total protein extracts from wild-type and Nrf2-KO MEFs against complex I subunit NDUFB8, complex II subunit $30 \mathrm{kDa}$, complex III subunit core 2, complex IV subunit II, and ATP synthase subunit $\alpha$ were performed with anti-OXPHOS (1:250; Mitosciences) antibody mixture according to the instructions of the manufacturer. Immunoreactive bands were visualized after processing the blots with horseradish peroxidase-conjugated secondary an- 
tibodies. Signals were detected using the ECL Western blotting detection system (Thermo Fisher Scientific). Densitometry analyses were performed using Quantity One Software (Bio-Rad).

$D M F$ and MMF administration in mice for neuroprotective studies against MPTP. Male C57BL/6 mice were treated with an acute MPTPintoxication paradigm to test the neuroprotective effects of DMF and MMF. Twelve-week-old C57BL/6 mice ( $n=8-10$ per group) were divided into four different groups: (1) a control group treated with saline alone; (2) a group treated with MPTP alone; (3) a group treated with either DMF or MMF (10, 50, or $\left.100 \mathrm{mg} \cdot \mathrm{kg}^{-1} \cdot \mathrm{d}^{-1}\right)$ alone; and (4) groups treated with DMF or MMF $\left(10,50\right.$, or $\left.100 \mathrm{mg} \cdot \mathrm{kg}^{-1} \cdot \mathrm{d}^{-1}\right)$ in combination with MPTP. Both DMF and MMF were dissolved in 1:4 ethanol/neobee oil (a derivative of coconut oil). MPTP at $10 \mathrm{mg} / \mathrm{kg}$ freebase was administered intraperitoneally three times a day $2 \mathrm{~h}$ apart. DMF or MMF was administered by oral gavage twice a day $12 \mathrm{~h}$ apart at a cumulative dose of 10,50 , and $100 \mathrm{mg} \cdot \mathrm{kg}^{-1} \cdot \mathrm{d}^{-1}$, respectively, $1 \mathrm{~d}$ before MPTP and daily for $5 \mathrm{~d}$ after MPTP. For investigation of markers of oxidative stress and inflammation, DMF $\left(100 \mathrm{mg} \cdot \mathrm{kg}^{-1} \cdot \mathrm{d}^{-1}\right.$ a day $12 \mathrm{~h}$ apart) was administered $2 \mathrm{~d}$ before MPTP and $2 \mathrm{~d}$ after MPTP. In both the regimens, DMF or MMF was not administered on the day of MPTP administration. Animals belonging to MPTP and control groups received the vehicle (ethanol/neobee oil, 1:4), whereas the drug-alone group received respective doses of DMF or MMF at the same frequency. 3-Nitrotyrosine (3-NT) and cluster of differentiation 68 (CD68) immunoreactivity were performed $48 \mathrm{~h}$ after the last dose of MPTP, whereas mRNA levels of proinflammatory markers were studied at $24 \mathrm{~h}$, and the neuroprotective studies were performed on day 7 after the last MPTP dose. For neuroprotective studies in wild-type and Nrf2-KO mice, 12week-old male Nrf2-KO and age-matched wild-type littermates were treated with $100 \mathrm{mg} \cdot \mathrm{kg}^{-1} \cdot \mathrm{d}^{-1} \mathrm{DMF}$ or MMF at a frequency similar to that described above. MPTP at $10 \mathrm{mg} / \mathrm{kg}$ freebase was administered three times a day $2 \mathrm{~h}$ apart, and animals in all experimental groups were killed on day 7 after MPTP administration.

$D M F$ and MMF administration in mice for assessment of Nrf2 target genes. Nrf2 target genes were determined after administration of DMF or MMF at a dose of $100 \mathrm{mg} \cdot \mathrm{kg}^{-1} \cdot \mathrm{d}^{-1}$ administered in $100 \mu \mathrm{l}$ of vehicle (ethanol/neobee oil, 1:4) by oral gavage $12 \mathrm{~h}$ apart. Control groups of mice received vehicle (ethanol/neobee oil, 1:4) at the same volume and frequency as DMF. Mice were killed, and the ventral midbrain and liver were collected at $6 \mathrm{~h}$ after the last dose of DMF and processed for RT-PCR analysis. Selectivity of DMF or MMF to activate the Nrf2/antioxidant response element (ARE) pathway was elucidated in an in vivo paradigm using Nrf2-KO and age-matched wild-type littermate mice by administering DMF at $100 \mathrm{mg} \cdot \mathrm{kg}^{-1} \cdot \mathrm{d}^{-1}$ as described above.

Measurement of tissue levels of fumarates by HPLC. Concentrations of MMF in the blood, liver, and brain of the mice after oral administration of DMF, MMF, or vehicle (ethanol/neobee oil, 1:4) was measured using a previously described method (Gennari et al., 2011). Briefly, brain and liver ( 200-400 mg) tissues were homogenized on ice in $0.5 \mathrm{ml}$ of methanol using a Tissue Miser (Thermo Fisher Scientific), whereas blood was mixed in methanol $(1: 1 \mathrm{v} / \mathrm{v})$. The homogenates were vortexed and then centrifuged at $21,000 \times \mathrm{g}$, at $4^{\circ} \mathrm{C}$, for $10 \mathrm{~min}$, and the supernatant was diluted with $500 \mu \mathrm{l}$ of HPLC-grade methanol. Supernatants (threefold the loop volume of $20 \mu \mathrm{l}$ ) were loaded on a Waters reverse-phase MS C18 column $(250 \times 4.6 \mathrm{~mm}$ inner diameter $)$ with water-acetonitrile at $60: 40 \mathrm{v} / \mathrm{v}$ mobile phase. A flow rate of $1.0 \mathrm{ml} / \mathrm{min}$ at $20 \pm 2^{\circ} \mathrm{C}$ was maintained. Fumarates were detected using a Waters UV detector set for a wavelength of $216 \mathrm{~nm}$. Analysis was performed using the Waters Breeze software package. Quantitation was made against standard curves generated by adding known concentrations of DMF and MMF.

Measurement of striatal levels of catecholamine and MPP ${ }^{+}$by HPLC. Striatal levels of DA and its metabolites 3,4,-dihydroxyphenylacetic acid (DOPAC) and homovanillic acid (HVA) were measured after sonication and centrifugation in chilled $0.1 \mathrm{M}$ perchloric acid (PCA; $100 \mu \mathrm{l} / \mathrm{mg}$ tissue) as described previously (Yang et al., 2009; Kaidery et al., 2013). Briefly, $15 \mu \mathrm{l}$ of supernatant was isocratically eluted through an $80 \times 4.6$ $\mathrm{mm} \mathrm{C18}$ column (ESA) with a mobile phase containing $0.1 \mathrm{M} \mathrm{LiH}_{2} \mathrm{PO}_{4}$, $0.85 \mathrm{~mm} 1$-octanesulfonic acid, and $10 \%(\mathrm{v} / \mathrm{v})$ methanol and detected by a two-channel Coulochem II electrochemical detector (ESA). Concen- trations of DA, DOPAC, and HVA were expressed as nanograms per milligrams protein. The protein concentrations of tissue homogenates were measured using the BCA assay (Thermo Fisher Scientific). For $\mathrm{MPP}^{+}$measurement, DMF or MMF was administered by oral gavage at $50 \mathrm{mg} / \mathrm{kg}$ in two divided doses separated by $12 \mathrm{~h}$ at $1 \mathrm{~d}$ before MPTP and again once $30 \mathrm{~min}$ before MPTP. Animals were killed $90 \mathrm{~min}$ after a single intraperitoneal administration of MPTP $(20 \mathrm{mg} / \mathrm{kg})$ freebase. Striatal tissues were sonicated and centrifuged in $0.1 \mathrm{M} \mathrm{PCA}$, and an aliquot of the supernatant was injected onto a Brownlee aquapore $\times 03224$ cation exchange column (Rainin). Samples were eluted isocratically with $20 \mathrm{~mm}$ boric acid-sodium borate buffer, $\mathrm{pH} 7.75$, containing $3 \mathrm{~mm}$ tetrabutylammonium hydrogen sulfate, $0.25 \mathrm{~mm}$ 1-heptanesulfonic acid, and $10 \%$ isopropanol. $\mathrm{MPP}^{+}$levels were detected with a fluorescence detector set for excitation at $295 \mathrm{~nm}$ and emission at $375 \mathrm{~nm}$ (Yang et al., 2009; Kaidery et al., 2013). Concentrations of $\mathrm{MPP}^{+}$were expressed as nanograms per milligrams tissue weight.

Measurement of GSH and oxidized glutathione levels by HPLC. For the intracellular GSH and oxidized glutathione (GSSG) levels, N27 rat dopaminergic cells and MEFs were treated with different doses (1-200 $\mu \mathrm{M})$ of DMF or MMF or DMSO as vehicle. Cells were sonicated in chilled $0.1 \mathrm{M}$ PCA and centrifuged, and $15 \mu \mathrm{l}$ of supernatant was isocratically eluted through a $4.6 \times 150 \mathrm{~mm} \mathrm{C18}$ column (ESA) with a mobile phase containing $50 \mathrm{~mm} \mathrm{LiH}{ }_{2} \mathrm{PO}_{4}, 1.0 \mathrm{~mm}$ 1-octanesulfonic acid, and 1.5\% (v/v) methanol and detected by a two-channel Coulochem III electrochemical detector (ESA), set at a guard cell potential of $950 \mathrm{mV}$ in Channel 1 for GSH and of $880 \mathrm{mV}$ in Channel 2 for GSSG detection (Yang et al., 2009; Kaidery et al., 2013). Concentrations of GSH and GSSG are expressed as nanomoles per milligram protein.

Measurement of GSH-fumarate adduct formation. Adduct formation during incubation of GSH with fumarates was monitored by liquid chromatography-mass spectrometry (LC-MS; Dibbert et al., 2013). One hundred microliters of a $10 \mathrm{~mm}$ solution of GSH in a PBS buffer, and 100 $\mu \mathrm{l}$ of a $10 \mathrm{~mm}$ DMF or $10 \mathrm{~mm}$ MMF solution in acetonitrile were added to $800 \mu \mathrm{l}$ of PBS, pH 7.4. The reaction mixture was kept at ambient temperature, and the reaction was monitored by MS spectroscopy (a Waters Acquity UPLC/MS system) by taking aliquots at fixed time intervals. Chromatographic separation was achieved on an Acquity UPLC BEH C18 $(2.1 \times 50 \mathrm{~mm}, 1.7 \mu \mathrm{m}$ particle size $)$ column with a flow rate of 0.75 $\mathrm{ml} / \mathrm{min}$ and mobile phases as follows: (A) water with $0.1 \% \mathrm{v} / \mathrm{v}$ formic acid; (B) acetonitrile with $0.1 \% \mathrm{v} / \mathrm{v}$ formic acid, with a mobile-phase gradient from 5 to $95 \%$ of B over 2 min. An analytical method using positive ion electrospray ionization was developed to detect GSH (protonated molecular ion in positive ionization mode $[\mathrm{M}+\mathrm{H}]^{+} 308$ ) and the DMF or MMF adducts, GS-DMF $\left([\mathrm{M}+\mathrm{H}]^{+}{ }^{4} 42\right)$ or GS-MMF $\left([\mathrm{M}+\mathrm{H}]^{+} 438\right)$. To generate the time course of GSH-fumarate adduct formation, GSH content was normalized to the initial content, whereas the adduct content was normalized to the final adduct content achieved.

Immunohistochemistry and morphometric analysis. Mice were anesthetized with sodium pentobarbital and transcardially perfused with $0.9 \%$ saline, followed by $4 \%$ paraformaldehyde in $0.1 \mathrm{~m}$ PBS, pH 7.4. Brains were dissected, postfixed in $4 \%$ paraformaldehyde for $24 \mathrm{~h}$, and cryopreserved in 30\% sucrose in PBS for $48 \mathrm{~h}$. Snap-frozen brains were coronally sectioned at $40 \mu \mathrm{m}$ thickness, encompassing the substantia nigra, using a cryostat. Sections were rinsed in PBS and incubated in 3\% hydrogen peroxide $/ 10 \%$ methanol solution for $10 \mathrm{~min}$ to quench endogenous peroxidase activity and permeabilized/blocked in $10 \%$ normal goat serum (NGS)/0.1\% Triton X-100/PBS for $1 \mathrm{~h}$ at room temperature. Sections were incubated overnight at $4{ }^{\circ} \mathrm{C}$ with the following primary antibodies in PBS containing 2\% NGS/0.01\% Triton X-100: rabbit polyclonal antityrosine hydroxylase (TH; 1:1000; Novus Biologicals), rat monoclonal anti-CD68 (1:500; Bio-Rad), and rabbit polyclonal anti-3-NT (1:100; Calbiochem). Biotinylated secondary antibodies (Jackson ImmunoResearch) were used appropriately, followed by incubation with streptavidin $\mathrm{ABC}$ solution (Vector Laboratories). Immunostaining was visualized by diaminobenzidine chromogen. Sections were mounted on glass slides, dehydrated, and coverslipped with Cytoseal (Thermo Fisher Scientific). Digital images were captured using a Zeiss Axioplan 2 microscope. THimmunostained sections were counterstained with thionin before dehydration and coverslipped with Cytoseal. Nissl (thionin)-stained and 
A

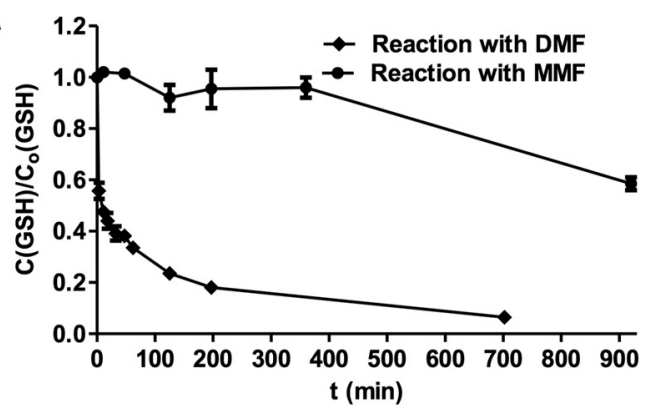

B

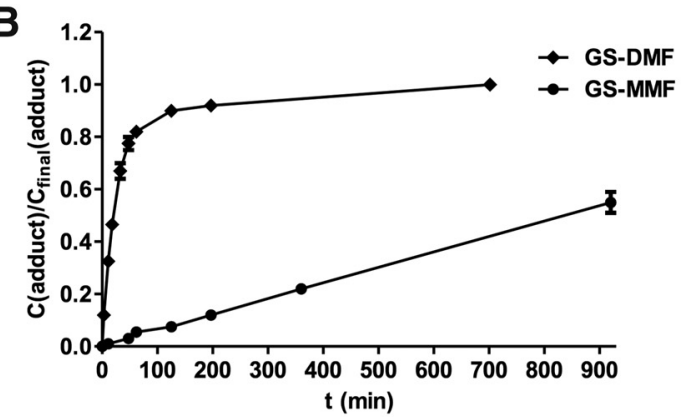

N27 rat dopaminergic cells
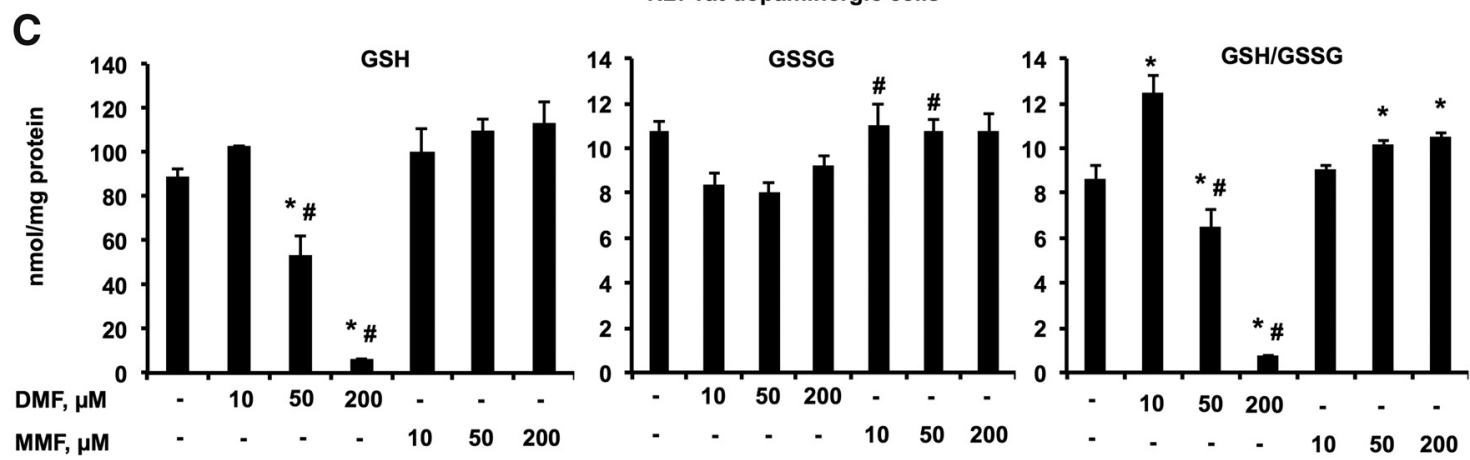

D

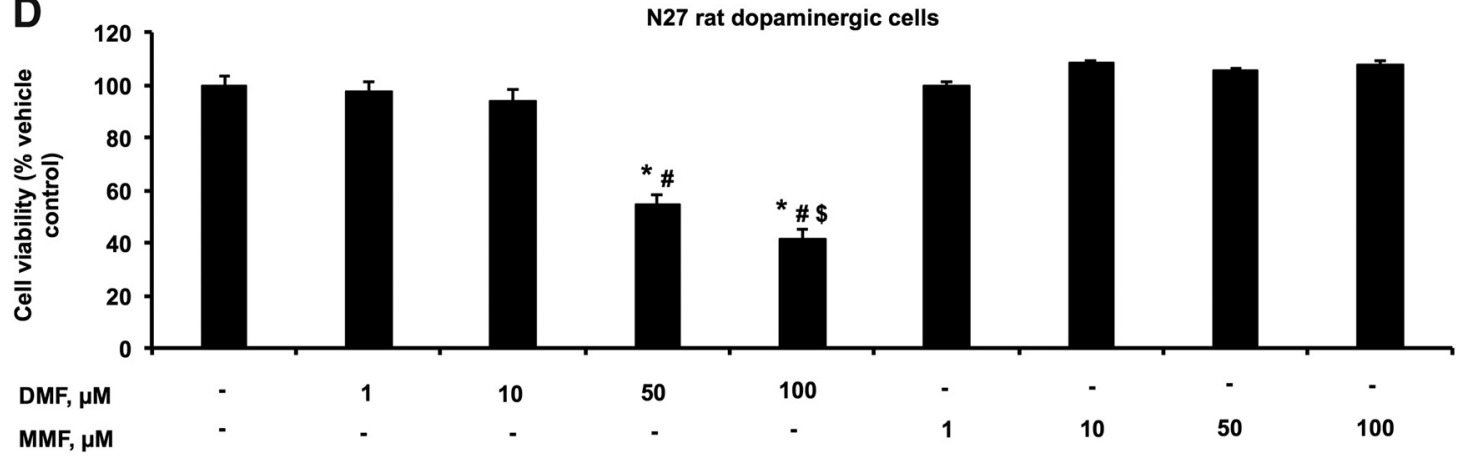

Figure 1. DMF forms an adduct with GSH and depletes intracellular GSH levels and decreases cell viability in a dose-dependent manner. Time course of the $S$-alkylation reaction between $1 \mathrm{~mm}$ DMF or $1 \mathrm{~mm}$ MMF with $1 \mathrm{~mm}$ GSH in PBS at pH 7.4 was measured as described in Materials and Methods. Time course for GSH consumption (A) and GS-DMF and GS-MMF adduct formation ( $\boldsymbol{B}$ ). $\boldsymbol{C}$, Intracellular GSH, GSSG, and their ratio (GSH/GSSG) were determined at $24 \mathrm{~h}$ after DMF and MMF (10,50, and $200 \mu \mathrm{M})$ treatment. Bars represent mean \pm SEM. ${ }^{*} p<0.05$ compared with controls; $\# p<0.05$ compared with DMF at $10 \mu \mathrm{M}(n=4)$. D. Cell viability in N27 rat dopaminergic cells treated with DMF $(1,10,50$, and $100 \mu \mathrm{M})$ or MMF $(1,10,50$, and $100 \mu \mathrm{M})$ for $24 \mathrm{~h}$ was assessed using Presto Blue cell viability kits. Bar plot represents the percentage of the control as mean \pm SEM of viable cells $(n=3) .{ }^{*} p<0.05$ compared with control (DMSO); $\#<0.05$ compared with the DMF $(1 \mu \mathrm{M})$-treated group; ${ }^{5} p<0.05$ compared with the DMF $(50 \mu \mathrm{m})$-treated group $(n=3)$.

TH-positive neuronal counts were estimated within the SNpc using Stereoinvestigator software (MicroBrightField) using a Zeiss Axioplan 2 microscope equipped with a motorized stage as described previously (Thomas et al., 2007). CD68-positive microglia were quantified on images captured from three coronal sections per mouse encompassing the substantia nigra. Quantitative analysis (cell number per square millimeter) was determined using NIH ImageJ software (Yin et al., 2010). SNpc 3-NT immunostaining was quantified by expressing the area occupied by the precipitate of 3-NT staining within the defined fields from three coronal sections per mouse (Kaidery et al., 2013).

Analysis of mitochondrial and glycolytic functions. The change in the mitochondrial bioenergetics and glycolysis after DMF and MMF exposure in wild-type and Nrf2-KO MEFs was assessed using an XF96 Analyzer (Seahorse Biosciences). Preliminary studies were performed to identify the optimum number of cells per well as $2 \times 10^{4}$ cells. Cells were exposed to DMSO, DMF (20-50 $\mu \mathrm{M})$, or MMF $(20-50 \mu \mathrm{M})$ for 4 and $24 \mathrm{~h}$. The XF96 culture microplates were then incubated in a $\mathrm{CO}_{2}$-free incubator at $37^{\circ} \mathrm{C}$ for $40 \mathrm{~min}$ to allow temperature and $\mathrm{pH}$ calibration. This was followed by sequential addition of oligomycin ( $1 \mu \mathrm{M}$ final concentration), carbonyl cyanide 4-(trifluoromethoxy) phenylhydrazone
( $1 \mu \mathrm{M}$ final concentration), and rotenone + antimycin A ( $1 \mu \mathrm{M}$ final concentration of each) to measure the OCR. These agents were used as per the instruction of the manufacturer to determine the basal mitochondrial respiration, oxygen consumption of ATP synthesis, reserve respiratory capacity, and maximal respiratory capacity in picomoles per minute of oxygen consumed. The drugs used were from the XF Cell Mito Stress Test kit (catalog \#102416-100; Seahorse Biosciences). To estimate changes in cellular glycolytic rates, cells were glucose-starved in XF assay medium in a $\mathrm{CO}_{2}$-free XF prep station at $37^{\circ} \mathrm{C}$ for $45 \mathrm{~min}$ and then sequentially injected with glucose $(2 \mathrm{mg} / \mathrm{ml}$ final concentration), oligomycin ( $1 \mu \mathrm{M}$ final concentration) and 2-deoxy-D-glucose (100 mM final concentration) to measure the extracellular acidification rate (ECAR); basal, maximal, and spare glycolytic capacity were determined, and the data were represented as $\mathrm{mpH}$ per minute.

Mitochondrial DNA copy number analysis. Mitochondrial DNA (mtDNA) copy number was determined using an established method described previously (Dumont et al., 2012). Briefly, wild-type and Nrf2-KO MEFs were incubated with DMF $(20 \mu \mathrm{M})$ and MMF $(20 \mu \mathrm{M})$ for $24 \mathrm{~h}$, and cells were collected using a cell scraper, followed by washing in serum-free DMEM. The total cellular DNA was extracted with a DNeasy 
A

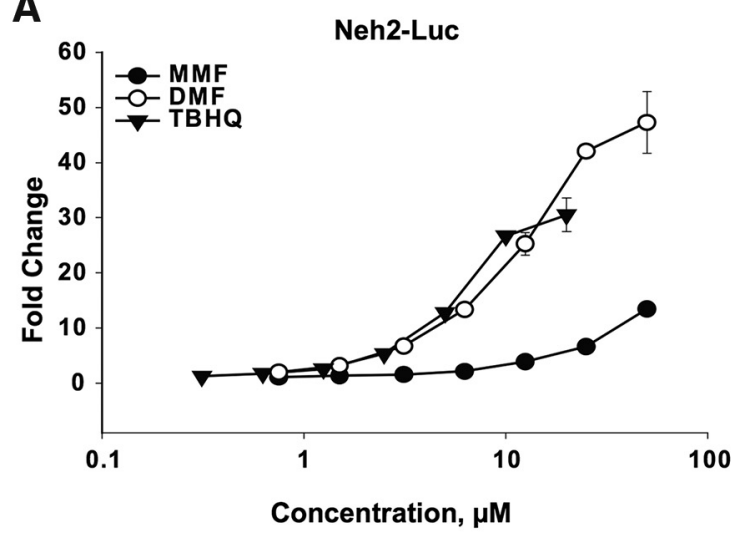

B

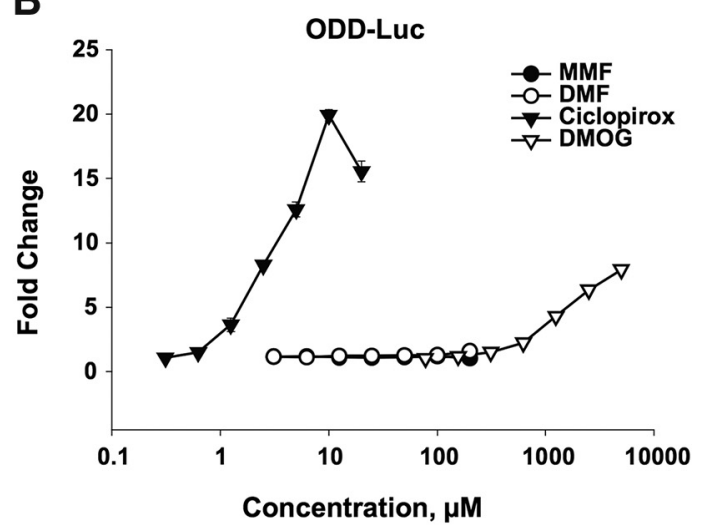

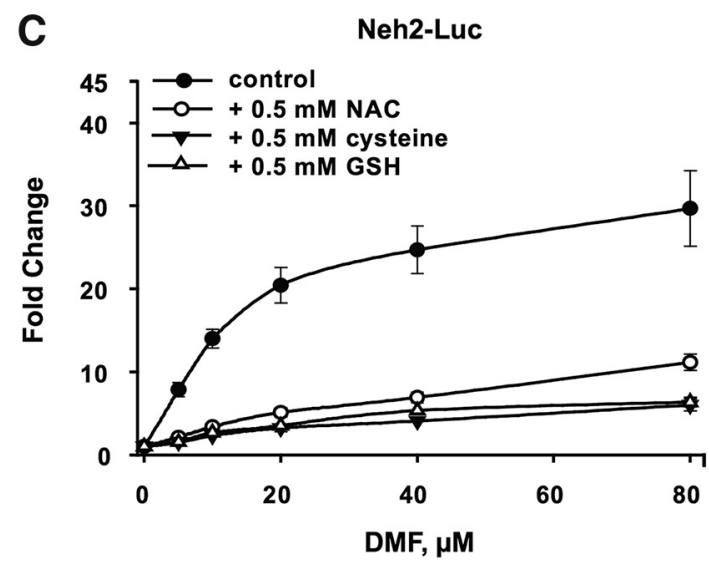

Figure 2. DMF directly activates the Nrf2 pathway via S-alkylation. $\boldsymbol{A}$, Dose-dependent activation of the Neh2-luc reporter by fumarate compounds (DMF and MMF) compared with the known Nrf2 activator TBHQ. B, Selectivity of fumarate compounds for Neh2-luc activation is shown compared with their activity toward the 0DD-luc reporter versus the potent HIF activator ciclopirox. Experiments were performed in triplicate, and the mean \pm SEM is plotted on the scatter plot. C, Quenching of the DMF dose-response curve in the Neh2-luc reporter assay during simultaneous incubation with thiol reagents: $0.5 \mathrm{~mm} N$-acetyl cysteine (NAC), cysteine, or GSH. Each experiment was performed in triplicate. The plot represents values of mean \pm SEM.

Blood \& Tissue kit (Qiagen) according to the protocol of the manufacturer. The relative mtDNA copy number was determined by qRT-PCR on an ABI PRISM 7900H Sequence Detection System (Applied Biosystems) using the Power SYBR Green PCR Master mix (Thermo Fisher Scientific) and pre-developed primers (IDT) for mitochondrial cytochrome oxidase 1 (Col) and $\beta$-actin (nuclear DNA control). Results were calculated from the threshold cycle values and expressed as the ratio of $2-\Delta \mathrm{CT}$ of $\mathrm{Co} 1$ to $\beta$-actin.

Statistical analysis. Results were expressed as means \pm SEM. Significance was determined by one-way or two-way ANOVA, followed by the Student-Newman-Keuls test or a two-tailed unpaired Student's $t$ test. Significance was set at $p \leq 0.05$. All statistical analyses were performed using Prism software (GraphPad Software).

\section{Results}

Nrf2 activation by DMF occurs via an S-alkylating mechanism and is accompanied by dose-dependent depletion of intracellular GSH and a decrease in cell viability

Fumarates, and DMF in particular, as a result of its nature as an $\alpha, \beta$-unsaturated carboxylic acid ester, can react spontaneously with thiols via a Michael-type addition (Schmidt et al., 2007). To illustrate the potency of DMF and MMF as alkylating agents, we ran the in vitro reaction of GSH derivatization by DMF and MMF as monitored by LC-MS. As can be seen in Figure $1, A$ and $B, 1 \mathrm{mM}$ GSH reacts with $1 \mathrm{~mm}$ DMF within the first few minutes of mixing, whereas MMF at similar concentrations is several orders of magnitude less reactive than DMF. Our results are consistent with those of a previously study on the mechanism and kinetics of $\mathrm{S}$-alkylated GSH formation in the course of an in vitro reac- tion with DMF and MMF under near-physiological conditions (Schmidt et al., 2007). GSH addition to DMF yields a 1:1 mixture of both diastereomeric 2-(S-glutathionyl)-succinic acid dimethyl esters, whereas MMF under identical reaction conditions leads to a mixture of four products (two diastereomeric pairs; Schmidt et al., 2007). Thus, DMF and MMF differ in their reactivity toward GSH and their S-alkylation mechanism: MMF reacts at a much lower rate, and the apparent first-order rate constant of GSH alkylation for MMF is 30-fold lower than for DMF, in accord with the published results (Schmidt et al., 2007). This result has been confirmed in this work by demonstrating a 90 -fold higher potency of DMF versus MMF to alkylate GSH in vitro (Fig. $1 A, B$ ). The best illustration of the alkylating power of DMF, but not MMF, is the depletion of intracellular GSH levels: administration of DMF to N27 rat dopaminergic cells (Fig. 1C) and MEFs (data not presented) depletes GSH in a dose-dependent manner, with almost complete depletion at $200 \mu \mathrm{M}$, whereas MMF in N27 rat dopaminergic cells (Fig. 1C) and MEFs (data not presented) at any dose within 10-200 $\mu \mathrm{m}$ had no effect on GSH levels (Fig. 1C). Consistent with GSH depletion, DMF administration in N27 cells (Fig. 1D) and MEFs (data not presented) induced significant cell death from doses of $50 \mu \mathrm{M}$ and above, whereas MMF at these doses did not induce cell death (Fig. 1D) in either of the cell types. Of note, both DMF and MMF have no effect on GSSG, whereas the ratio of reduced/oxidized GSH showed an increase at a low dose of DMF $(10 \mu \mathrm{M})$ with significant decreases at higher doses (50 and $200 \mu \mathrm{M}$ ), whereas MMF treatment significantly increa- 
A

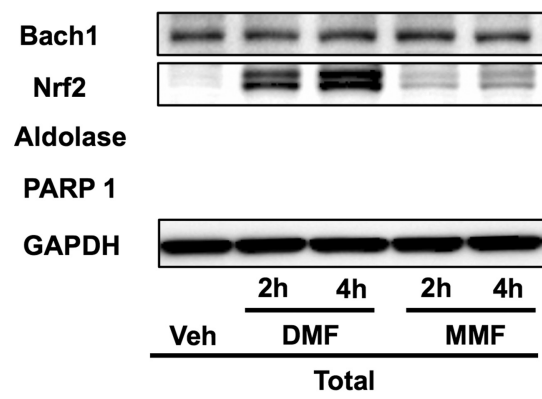

M17 human neuroblastoma cells

B
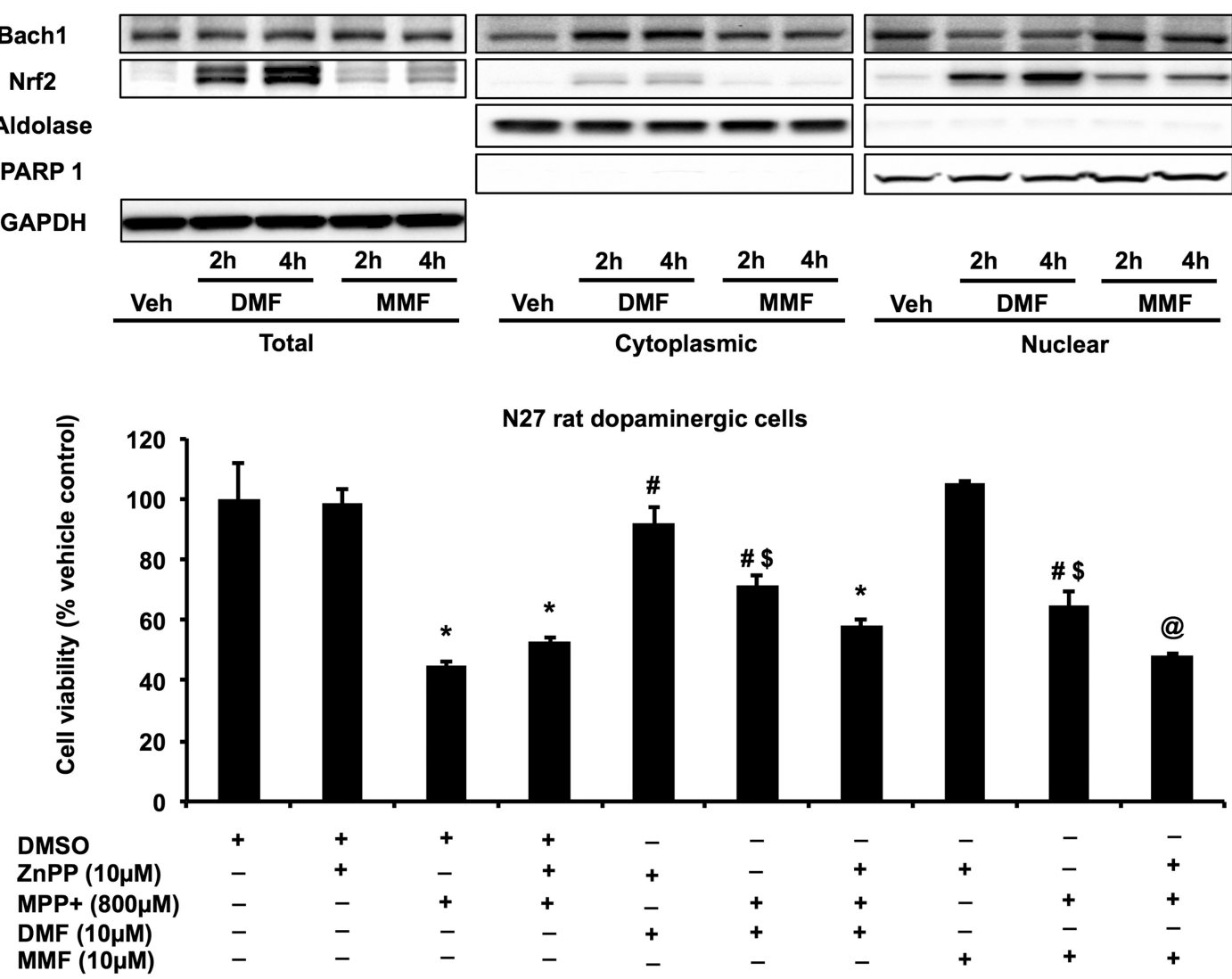

Figure 3. Nrf2 activation of DMF and MMF involves Bach1 nuclear export and is associated with Hmox1-mediated neuroprotection. A, Immunoblot showing total, nuclear, and cytosolic Bach1 and Nrf2 levels after a 2 and $4 \mathrm{~h}$ incubation with DMF (10 $\mu \mathrm{M})$ or MMF (10 $\mu \mathrm{M})$ in human BE(2)-M17 neuroblastoma cells. GAPDH was used as a loading control for the total fraction, whereas aldolase and PARP1 were used to verify the purity and to demonstrate equal loading of the cytosolic and nuclear fraction, respectively. B, Cell viability in N27 rat dopaminergic cells treated with DMF (10 $\mu \mathrm{M}$ ) or MMF $(10 \mu \mathrm{M})$ in the presence or absence of MPP ${ }^{+}$and/or ZnPP. Plot represents percentage control as mean \pm SEM of viable cells $(n=3)$. ${ }^{*} p<0.05$ compared with DMSO control; ${ }^{\#} p<0.05$ compared with the MPP ${ }^{+}$-treated group; ${ }^{\$} p<0.05$ compared with the DMSO $+\mathrm{ZnPP}+\mathrm{MPP}^{+}$-treated group; ${ }^{\circledR} p<0.05$ compared with the MPP ${ }^{+}+$MMF-treated group. $^{\circ}$

sed the ratio of reduced/oxidized GSH levels at higher doses (Fig. 1C).

To compare the Nrf2-activating potential of DMF and its analog MMF, we used a $p_{c m v}$-driven Neh2-luc reporter. The Neh2luc reporter results in constitutive, intracellular synthesis of a novel fusion protein composed of the Neh2 domain of Nrf2 and firefly luciferase. The Neh2 domain of Nrf2 protein is known to bind to Keap 1 and is sufficient for recognition by the ubiquitinligase complex and subsequent ubiquitinylation and degradation of the fusion protein. Thus, the Neh2-luc reporter is a perfect tool to monitor the direct effect of a compound on the first step controlling Nrf2 stability, that is, Nrf2-Keap1 and/or Keap1-Cul3 interactions (Smirnova et al., 2011). DMF was compared with TBHQ, a well known Nrf2 activator, and found to be indistinguishable, within experimental error, in activating Nrf2 (Fig. 2A). Conversely, MMF was 10-fold less active in the Neh2-luc reporter assay compared with DMF or TBHQ (Fig. 2A). One may expect much lower activation of the Neh2-luc reporter in the case of MMF given its 30-fold lower alkylating ability than that of DMF and the lower membrane permeability of MMF because of the one free, unmethylated carboxylic group preserved in its structure. The fact that MMF is only 10 -fold less potent in activation of the cell-based reporter indirectly suggests a more specific interaction of MMF with Keap1 thiols versus less specific DMF. The absence of a DMF or MMF effect in the HIF ODD-luc reporter assay in the studied concentration range confirms the specificity of fumarate action on the Neh2-luc reporter (Fig. 2B).
The mechanism of Neh2-luc reporter activation is based on alkylation of active cysteines in Keap1 (Linker et al., 2011). Based on DMF and MMF in vitro reactivity toward cysteine in GSH, a 30-fold difference in $\mathrm{EC}_{50}$ between DMF and MMF would be expected in the Neh2-luc reporter assay. The lower difference in activation parameters between DMF and MMF in the cell-based assay may reflect significant quenching of DMF by intracellular GSH compared with MMF. To illustrate this possibility, we used simultaneous addition of DMF and reducing agents, such as GSH, cysteine, or $\mathrm{N}$-acetyl cysteine (only the latter is cell permeable), to the Neh2-luc reporter cell line: $0.5 \mathrm{~mm}$ thiols strongly quenched Neh2-luc reporter activation (Fig. 2C). At 1-2 mM thiols, the reporter showed no activation with DMF at all (data not presented). These results suggest that the superior reactivity of DMF toward Keap1 thiols (Linker et al., 2011) and its ability to activate Nrf2 in the Neh2-luc reporter in vitro (Fig. 2A) directly originates from its alkylating nature.

\section{Nrf2 activation by DMF and MMF is associated with Bach1} nuclear export

Several studies have demonstrated Bach1 (BTB and CNC homology) to be a transcriptional repressor of Nrf2 in the regulation of oxidative stress and ARE activation (Igarashi and Sun, 2006). Bach 1 acts as physiological antagonist of Nrf2 and binds to the ARE sequences on the DNA, thus inhibiting transcriptional activation by Nrf2. During Nrf2 activation, Bach1 export from the nucleus is essential to allow binding of Nrf2 to 

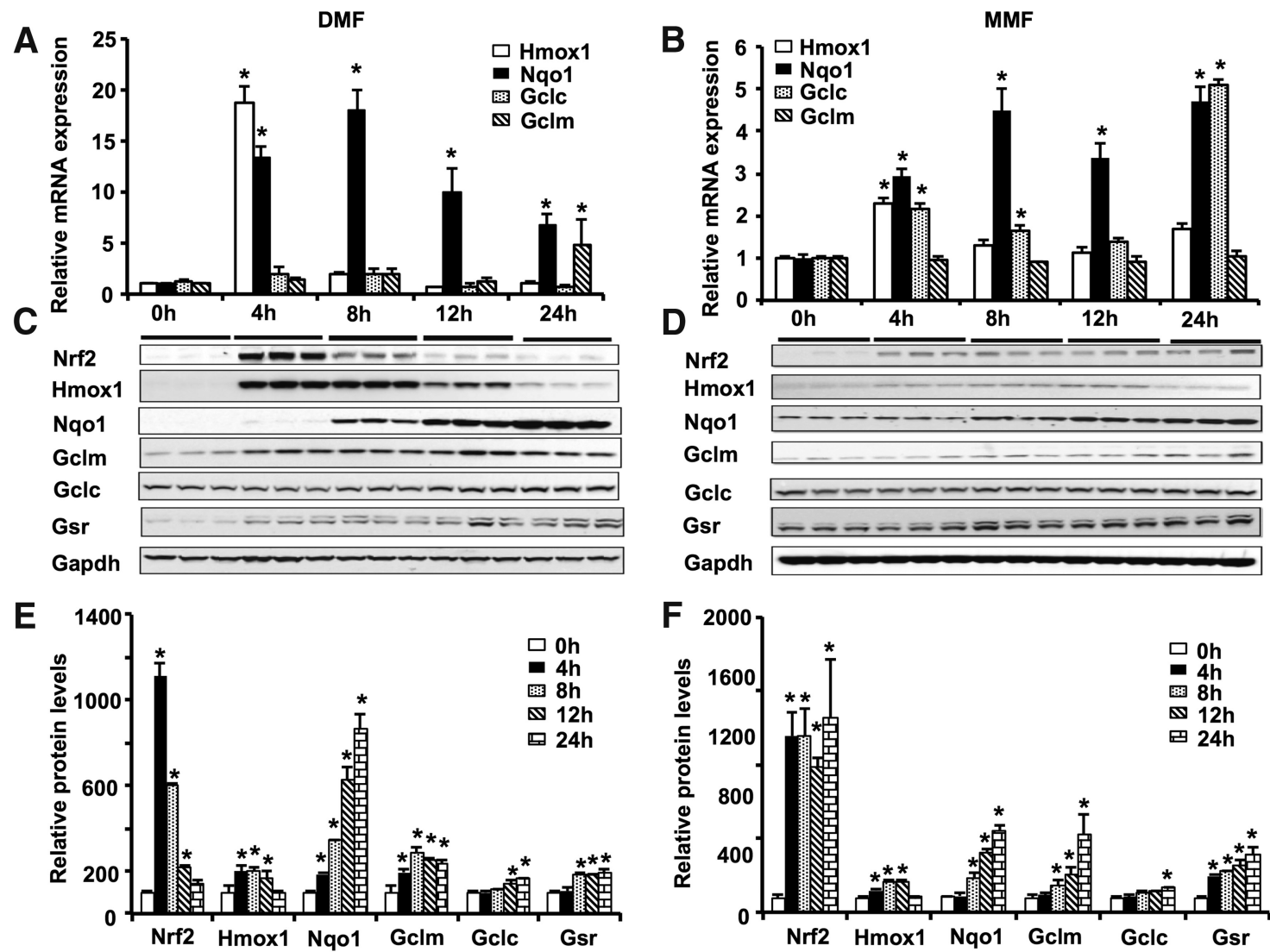

Figure 4. DMF and MMF activate Nrf2/ARE signaling in vitro. $\boldsymbol{A}, \boldsymbol{B}, \mathrm{qRT}-\mathrm{PCR}$ analysis showing relative mRNA levels of ARE-containing genes after DMF (20 $\mu \mathrm{m} ; \boldsymbol{A})$ and MMF (20 $\mu \mathrm{M} ; \boldsymbol{B})$ administration. Bars represent mean $\pm S E M .{ }^{*} p<0.05$ compared with respective controls $(n=3$ per time point). Immunoblot analysis $(\boldsymbol{C}, \boldsymbol{D})$ and densitometry analysis $(\boldsymbol{E}, \boldsymbol{F})$ of ARE proteins and the changes in ARE-containing proteins after DMF $(20 \mu \mathrm{M} ; \boldsymbol{C}, \boldsymbol{E})$ and MMF $(20 \mu \mathrm{M} ; \boldsymbol{D}, \boldsymbol{F})$ treatment. Bars represent percentage control values depicted as mean \pm SEM. ${ }^{*} p<0.05$ compared with respective controls ( $n=5$ per time point).

these ARE sequences in the regulatory regions of the AREcontaining genes after nuclear translocation of Nrf2. To further confirm differences between DMF and MMF on Nrf2 activation, we compared export of Bach1 from the nucleus to the cytosol during Nrf2 activation. Because of the lack of good quality rodent-specific commercially available Bach 1 antibodies, we used human M17 neuroblastoma cells treated with DMF $(10 \mu \mathrm{M})$ and MMF $(10 \mu \mathrm{M})$ for 2 and $4 \mathrm{~h}$. Immunoblot analysis of Bach1 in the total, nuclear, and cytosolic fractions of DMF- and MMF-treated M17 cells showed increased cytosolic and reduced nuclear Bach1 levels after DMF and MMF treatment (Fig. 3A). Both DMF and MMF increased cytosolic levels of Bach; however, the amount of Bach1 exported from the nucleus to the cytosol by DMF was greater than with MMF treatment. Similarly, nuclear translocation of Nrf2 protein from the cytosol increased after DMF and MMF, with DMF treatment leading to more nuclear Nrf2 compared with MMF (Fig. 3A). This is consistent with the ability of DMF to activate the Nrf2 pathway in vitro more robustly than MMF at these doses (Fig. 2).

To determine differences between DMF and MMF on Bach1 nuclear export and downstream events associated with Bach1 nuclear export, we studied the role of an ARE gene in cytoprotection. Hmox 1 is one of the ARE-containing genes heavily regulated by Bach1 because the Hmoxl promoter is known to have a large number of ARE sequences to which Nrf2 can bind to induce its expression preferentially (Kensler et al., 2007). The enzymatic activity of Hmoxl involves catalyzing the degradation of heme to produce carbon monoxide, iron, and biliverdin, which are well known cellular antioxidant and anti-inflammatory agents known to induce neuroprotective effects (Otterbein et al., 2003). To determine the potential association of Bach1 nuclear export and Hmox1-mediated underlying neuroprotective mechanisms, we studied the neuroprotective effects of DMF and MMF against $\mathrm{MPP}^{+}$toxicity in N27 rat dopaminergic cells with or without the presence of ZnPP, a widely used inhibitor of Hmoxl activity (Liu et al., 2014). As shown in Figure $3 B, \mathrm{MPP}^{+}$induced significant cell death in N27 cells after $24 \mathrm{~h}$, which was attenuated by pretreatment with either DMF $(10 \mu \mathrm{M})$ or MMF $(10 \mu \mathrm{M})$. However, ZnPP $(10 \mu \mathrm{M})$ added 10 min before MMF and DMF significantly blocked the neuroprotective effect of both DMF and MMF against $\mathrm{MPP}^{+}$toxicity. Neuroprotective effects against $\mathrm{MPP}^{+}$toxicity was observed for DMF (at doses of 1-20 $\mu \mathrm{M}$ ) and MMF (1-100 $\mu \mathrm{M})$, whereas higher doses of DMF (50-200 $\mu \mathrm{M})$ induced significant toxicity to N27 cells and MMF at the studied doses had no effect on cell viability (data not presented). $\mathrm{ZnPP}(10 \mu \mathrm{M})$ blocked $>80 \%$ of Hmox 1 activity (data not presented). The ZnPP treatment either alone or in combination with DMF or MMF did not affect cell viability significantly when compared with controls and when compared between $\mathrm{MPP}^{+}$with and without $\mathrm{ZnPP}$ (Fig. 3B). This suggests that a functionally active Hmoxl mediates the neuroprotective effect of DMF and MMF against $\mathrm{MPP}^{+}$ toxicity. 

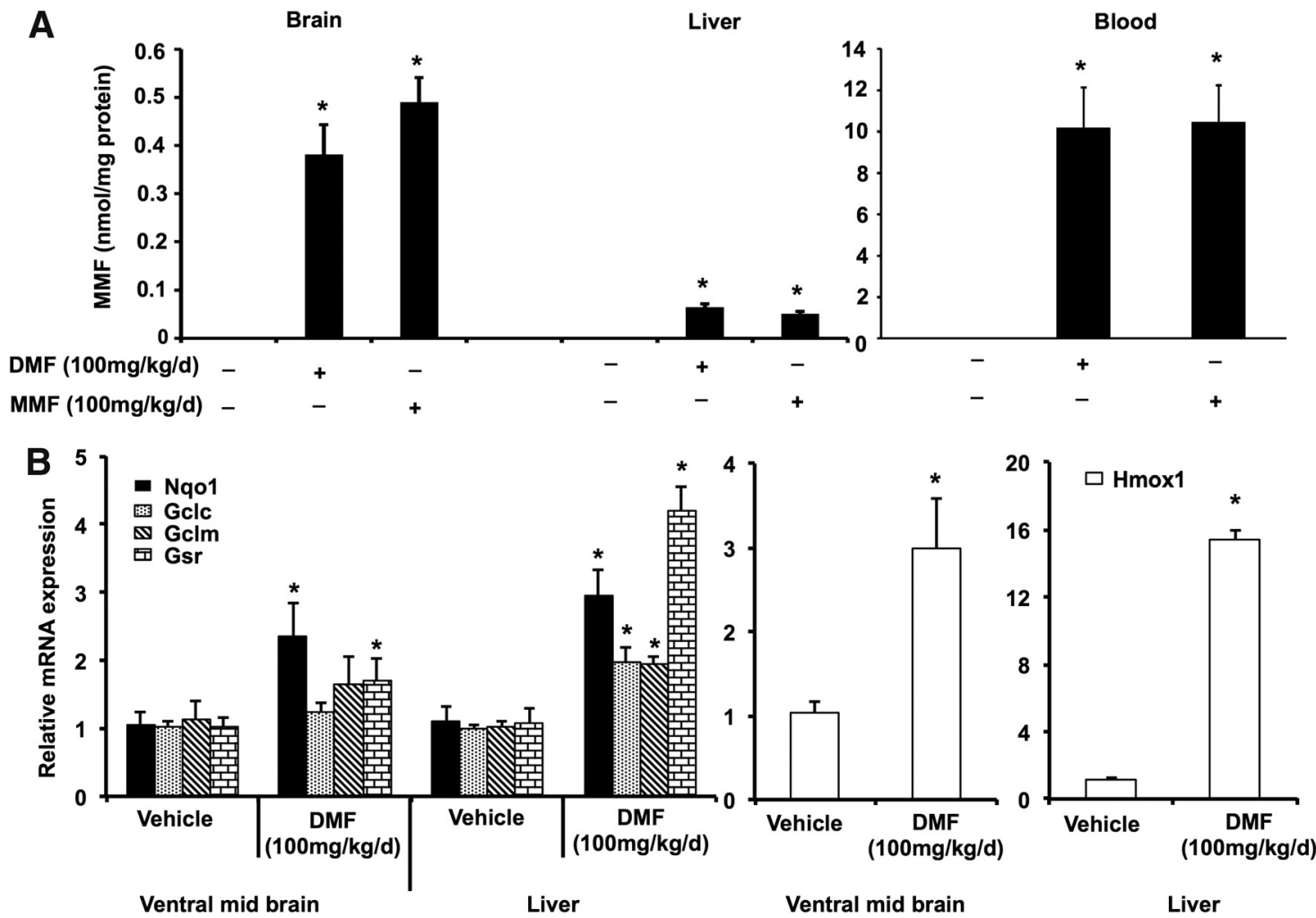

Figure 5. Bioavailability of DMF and MMF and in vivo activation of ARE-containing genes by DMF. $A$, Levels of MMF in the brain, liver, and blood of C57BL/ $6 \mathrm{mice}$ after two doses of $50 \mathrm{mg} / \mathrm{kg}$ (or $\left.100 \mathrm{mg} \cdot \mathrm{kg}^{-1} \cdot \mathrm{d}^{-1}\right)$ DMF or MMF administered $12 \mathrm{~h}$ apart by oral gavage and measured at $6 \mathrm{~h}$ after the last dose. Bars represent mean \pm SEM $\left(n=5\right.$ mice per group). ${ }^{*} p<0.05$ compared with respective vehicle controls. $B$, Quantitative RT-PCR showing relative mRNA levels of ARE-containing genes in the ventral midbrain and liver after two doses of $50 \mathrm{mg} / \mathrm{kg}$ DMF administered $12 \mathrm{~h}$ apart by oral gavage and measured at $6 \mathrm{~h}$ after the last dose. Bars represent mean \pm SEM ( $n=5$ mice per group). ${ }^{*} p<0.05$ compared with vehicle controls.

Differential activation of the Nrf2 pathway by DMF and MMF in $\mathrm{N} 27$ rat dopaminergic cells

To confirm the Neh2-luc reporter activation and downstream Bach1 export mechanisms by fumarates, we tested the ability of DMF and MMF to activate the Nrf2 pathway in N27 rat dopaminergic cells. Based on the data from the Neh2-luc reporter assay, we chose a $20 \mu \mathrm{M}$ concentration of DMF and MMF to measure Nrf2 target genes in the N27 cells at different time points of 0,4 , 8, 12, and $24 \mathrm{~h}$ (Fig. 4). This dose of DMF and MMF was chosen because it did not affect cellular levels of reduced and oxidized GSH but induced cytoprotective effects in vitro (data not presented). Relative mRNA expression assessment of target genes showed upregulation of Hmoxl and Nqol at $4 \mathrm{~h}$ by DMF and MMF, although with MMF the activation was not as robust compared with DMF (Fig. 4A,B). Although Nqo1 showed upregulation for a prolonged period of time (beyond $24 \mathrm{~h}$ ), Hmoxl expression returned to control levels by $24 \mathrm{~h}$. Consistent with the upregulation of mRNA levels of Nrf2 target genes, protein levels of Nrf2, glutamate-cysteine ligase, Gclm, Gclc, Nqo1, Hmox1, and Gsr were also significantly increased between 4 and $24 \mathrm{~h}$ after the treatments (Fig. $4 C-F$ ). Together, measurement of Nrf2 and its target genes in N27 dopaminergic cells confirmed Nrf2 activation by DMF and MMF and suggested that DMF is a stronger Nrf2 activator in vitro compared with MMF.

\section{DMF and MMF activate the Nrf2 pathway in vivo}

Next, we tested the ability of DMF to activate Nrf2 signaling in vivo in mice. Dose selection for these studies were selected following a small pharmacodynamics assay to confirm that both DMF and MMF cross the blood-brain barrier and activate the Nrf2 pathway in the brain. Previous studies have reported that DMF undergoes rapid systemic metabolism to its bioactive metabolite MMF (Sheikh et al., 2013). Therefore, to test the bioavailability of DMF in vivo, we measured MMF levels in the C57BL/6 mice. Twelve-week-old male C57BL/6 mice were administered 10,50 , and $100 \mathrm{mg} \cdot \mathrm{kg}^{-1} \cdot \mathrm{d}^{-1}$ DMF and MMF by oral gavage in two divided doses separated by $12 \mathrm{~h}$. Mice were killed at different time points ( $30 \mathrm{~min}$ to $6 \mathrm{~h}$ ) after the last dose of the drugs, and various tissues were collected. Both DMF and MMF administration resulted in a dose-dependent increase in MMF levels in vivo within $30 \mathrm{~min}$ after drug administration (data not presented), with the highest levels of MMF observed at a dose of $100 \mathrm{mg} \cdot \mathrm{kg}^{-1} \cdot \mathrm{d}^{-1}$ in blood and brain at $6 \mathrm{~h}$ (Fig. $5 A$ ). However, the levels of MMF in the liver were found to be lower than the levels in the blood and brain, consistent with previous reports showing maximum levels in kidney and brain rather than liver (http:// www.ema.europa.eu/docs/en_GB/document_library/EPAR_-_ Public_assessment_report/human/002601/WC500162070.pdf). Analysis of mRNA levels of downstream Nrf2 target genes by qRT-PCR analysis showed a dose-dependent increase in the Nrf2 target genes in both the liver and brain (data not presented). Maximal increase in the mRNA levels (3- to 12-fold) were observed in the liver for Nrf2 target genes such as Gclm, Gclc, Hmox 1 , and Gsr at $6 \mathrm{~h}$ after $100 \mathrm{mg} \cdot \mathrm{kg}^{-1} \cdot \mathrm{d}^{-1}$ DMF (Fig. 5B) or MMF (data not presented). Ventral midbrain mRNA levels of Hmox1, Nqo1, and Gsr were also significantly upregulated by DMF and MMF. However, genes involved in the GSH biosynthetic machinery, such as Gclm and Gclc, were not upregulated (Fig. $5 B$ ). Unlike the in vitro situation in which DMF induced stronger Nrf2 activation than MMF, in vivo both DMF and MMF induced Nrf2 target genes with similar potency. Collectively, 


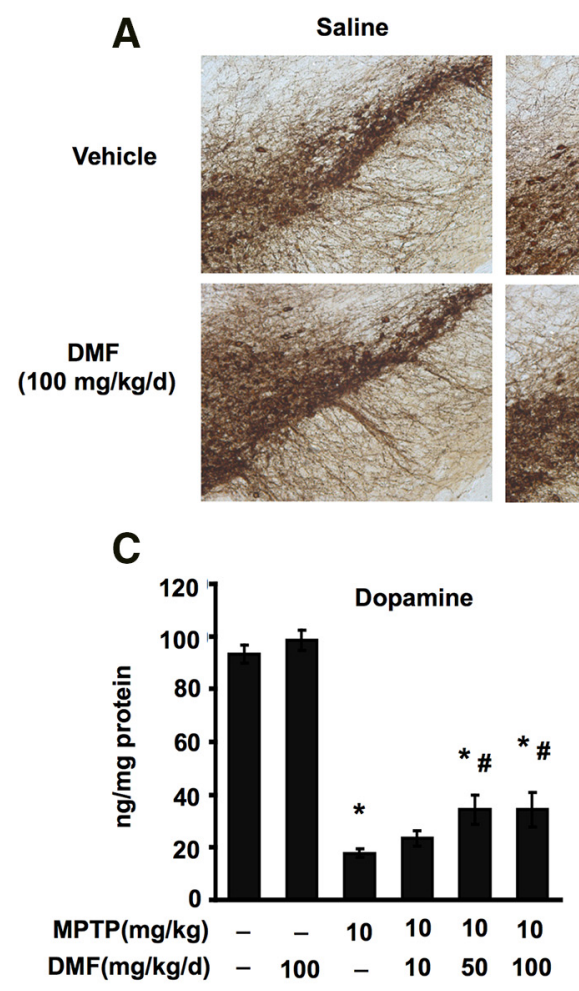

MPTP

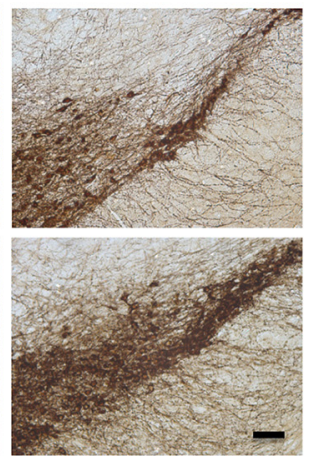

B

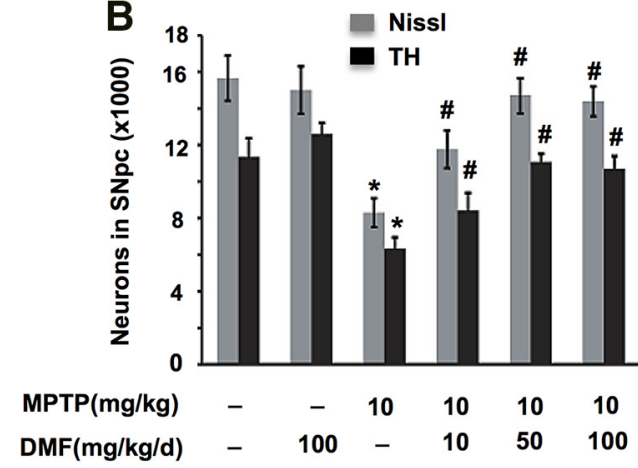

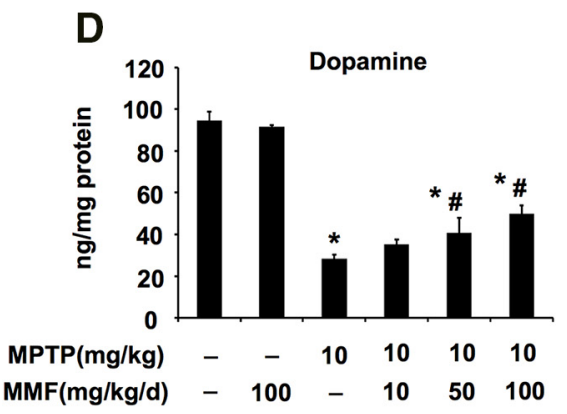
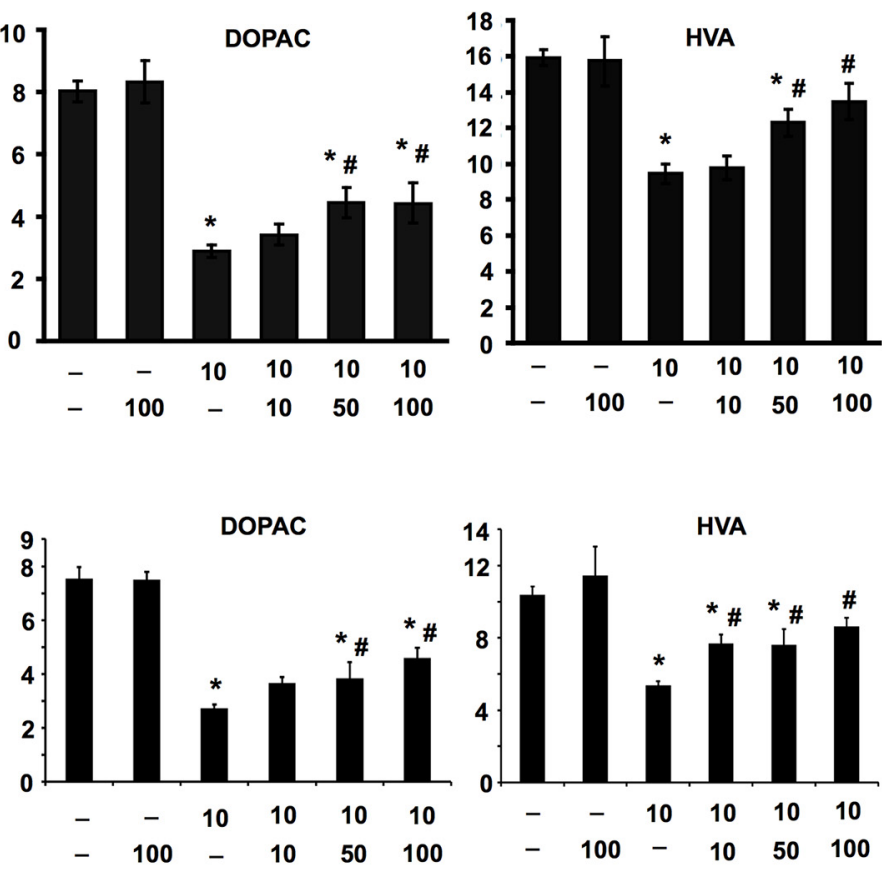

Figure 6. Neuroprotective effects of DMF and MMF in the MPTP model of PD. Immunohistochemical staining for TH $(\boldsymbol{A})$ and stereological analysis of total (Nissl) and TH ${ }^{+}$neurons $(\boldsymbol{B})$ in the SNpc in the acute MPTP model on day 7 after treatment with different doses of $D M F\left(10,50\right.$, and $100 \mathrm{mg} \cdot \mathrm{kg}^{-1} \cdot \mathrm{d}^{-1}$, administered in 2 divided doses via oral gavage) for $6 \mathrm{~d}$. Bars represent mean \pm SEM. ${ }^{*} p<0.05$ compared with saline controls; ${ }^{\#} p<0.05$ compared with MPTP $(n=6-10$ mice per group). Striatal levels of DA and its metabolites DOPAC and HVA after DMF (C) or MMF (D) treatment as measured by HPLC-electrochemical detection analysis in the acute MPTP model on day 7. Bars represent mean \pm SEM. ${ }^{*} p<0.05$ compared with saline controls; ${ }^{\#} p<0.05$ compared with MPTP ( $n=6-10$ mice per group). Scale bar, $100 \mu \mathrm{m}$.

these data provide in vivo pharmacokinetic profiles of DMF and MMF and their ability to activate Nrf2-mediated gene transcription in vivo.

DMF and MMF protect against MPTP neurotoxicity in mice A widely used animal model that recapitulates many of the neuropathologic features of PD and is used as an initial screening tool to test potential treatments is the MPTP mouse model (Blesa and Przedborski, 2014). Using this model, we previously showed attenuation of MPTP neurotoxicity by experimental compounds that can activate the Nrf2 pathway (Yang et al., 2009; Kaidery et al., 2013). Hence, we sought to test whether activation of Nrf2 signaling by the fumaric acid esters DMF and MMF can induce a neuroprotective response against MPTP neurotoxicity. To determine this, we used an acute MPTP-based PD mouse model, in which three injections of $10 \mathrm{mg} / \mathrm{kg}$ MPTP is administered every $2 \mathrm{~h}$ on a single day in 12-week-old male mice, resulting in significant loss of striatal DA (75\%) and its metabolites DOPAC and HVA (50\%) and a significant loss of TH-immunopositive neu- rons in the SNpc on day 7. Administration of DMF at 10,50, and $100 \mathrm{mg} \cdot \mathrm{kg}^{-1} \cdot \mathrm{d}^{-1} 1 \mathrm{~d}$ before and then for $5 \mathrm{~d}$ after MPTP administration dose dependently protected against MPTPinduced loss of TH-immunopositive neurons in the SNpc on day 7 (Fig. $6 A, B$ ). Unbiased stereologic cell counts of total (i.e., Nisslpositive) and TH-positive neurons in the SNpc showed a statistically significant loss of neurons after MPTP compared with controls (Fig. 6B). Administration of DMF, at 10, 50, and 100 $\mathrm{mg} \cdot \mathrm{kg}^{-1} \cdot \mathrm{d}^{-1}$, showed a significant dose-dependent attenuation of MPTP-induced loss of total (i.e., Nissl-positive) and THimmunopositive neurons compared with MPTP-treated mice (Fig. 6B). Assessment of striatal DA and its metabolites DOPAC and HVA showed a significant loss after MPTP on day 7, which was attenuated by DMF, administered at 50 and 100 $\mathrm{mg} \cdot \mathrm{kg}^{-1} \cdot \mathrm{d}^{-1}$ (Fig. 6C). However, DMF at $10 \mathrm{mg} \cdot \mathrm{kg}^{-1} \cdot \mathrm{d}^{-1}$ only showed a trend for a protective response for striatal levels of DA and DOPAC compared with MPTP, which did not achieve significance. Only the HVA levels showed a statistically significant protective response of $10 \mathrm{mg} \cdot \mathrm{kg}^{-1} \cdot \mathrm{d}^{-1} \mathrm{DMF}$ against 
A

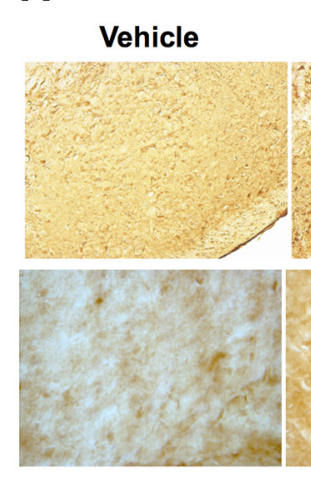

C

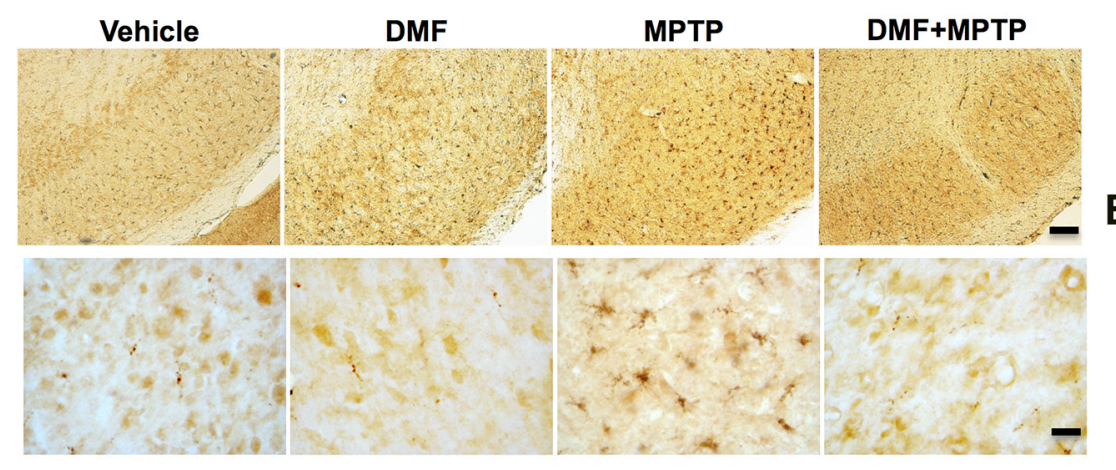

3-Nitrotyrosine

DMF

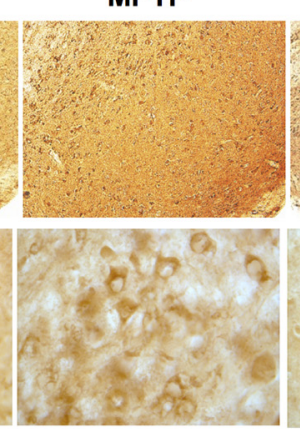

CD68
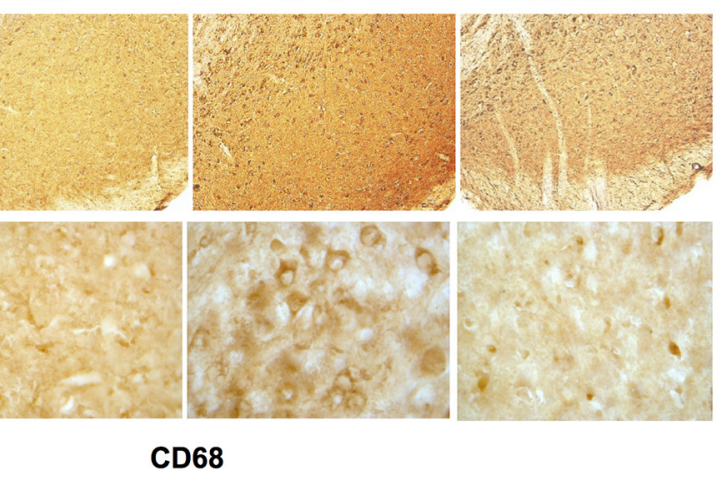

DMF+MPTP

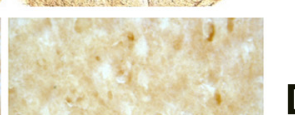

E

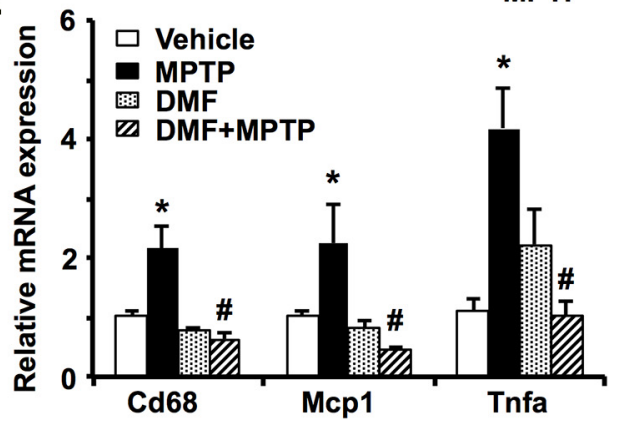

Figure 7. DMF attenuates MPTP-induced accumulation of oxidative stress and inflammation. $A$, Accumulation of oxidative stress in the substantia nigra demonstrated by $3-N T$ immunoreactivity $48 \mathrm{~h}$ after acute MPTP with and without DMF $\left(100 \mathrm{mg} \cdot \mathrm{kg}^{-1} \cdot \mathrm{d}^{-1}\right)$ administration; representative images from $n=3$ mice in each group. Scale bar, $100 \mu \mathrm{m} . B$, Quantitative comparison of area of 3-NT immunoreactivity in SNpc $48 \mathrm{~h}$ after MPTP and after DMF treatment. Bars represent mean \pm SEM. ${ }^{*} p<0.05$ compared with saline controls; ${ }^{\#} p<0.05$ compared with MPTP $(n=5)$. C, CD68-immunoreactive microglia in the substantia nigra $36 \mathrm{~h}$ after acute MPTP and treatment with DMF. Representative images from $n=3$ mice in each group. Scale bar, $100 \mu \mathrm{m}$. D, CD68-positive microglial cell counts in the substantia nigra $36 \mathrm{~h}$ after acute MPTP and treatment with DMF. Bars represent mean \pm SEM. ${ }^{*} p<0.05$ compared with saline controls; ${ }^{\#} p<0.05$ compared with MPTP $(n=5)$. E, Levels of proinflammatory genes measured $24 \mathrm{~h}$ after the last dose of acute MPTP and after DMF treatment. Bars represent mean \pm SEM. ${ }^{*} p<0.05$ compared with saline controls; ${ }^{\#} p<$ 0.05 compared with MPTP $(n=5)$.

MPTP toxicity (Fig. 6C). Given that DMF is immediately metabolized to its active metabolite MMF in vivo, we also compared neuroprotective effects of MMF against MPTP neurotoxicity administered at similar doses and frequency as DMF (Fig. 6D). MMF administration protected against MPTP neurotoxicity in a similar manner as DMF, with the higher doses of 50 and 100 $\mathrm{mg} \cdot \mathrm{kg}^{-1} \cdot \mathrm{d}^{-1}$ markedly attenuating MPTP-induced loss of striatal DA, DOPAC, and HVA (Fig. 6D), whereas the lower dose of MMF $\left(10 \mathrm{mg} \cdot \mathrm{kg}^{-1} \cdot \mathrm{d}^{-1}\right)$ significantly increased the levels of HVA but not DA and DOPAC compared with MPTP (Fig. 6D). To rule out the possibility of DMF or MMF impairing the conversion of MPTP to $\mathrm{MPP}^{+}$to result in neuroprotection, striatal $\mathrm{MPP}^{+}$levels were measured $90 \mathrm{~min}$ after a single intraperitoneal injection of MPTP $(20 \mathrm{mg} / \mathrm{kg}$ freebase $)$ after pretreatment with vehicle (1:4, ethanol/neobee oil) and DMF or MMF $(100 \mathrm{mg} / \mathrm{kg})$ $1 \mathrm{~h}$ before administration of MPTP. $\mathrm{MPP}^{+}$levels in DMF-treated $(9.88 \pm 1.62 \mathrm{ng} / \mathrm{mg}$ tissue $)$ or MMF-treated $(9.52 \pm 1.74 \mathrm{ng} / \mathrm{mg}$ tissue) mice were not significantly different compared with those in vehicle-treated mice $(9.32 \pm 1.09 \mathrm{ng} / \mathrm{mg}$ tissue $)$, suggesting that neuroprotective actions of DMF and MMF do not involve blocking the conversion of MPTP to $\mathrm{MPP}^{+}$. Collectively, these results demonstrate the in vivo neuroprotective actions of both DMF and MMF in a neurotoxin-induced mouse model of PD.

\section{DMF blocks MPTP-induced oxidative stress}

and neuroinflammation

The acute paradigm of MPTP toxicity is known to cause nonapoptotic neuronal degeneration by triggering events that can lead to progressive neuroinflammation and oxidative stress (Thomas et al., 2012; Banerjee et al., 2015). Several studies including ours demonstrate that Nrf2-mediated gene transcription modulates cellular oxidative stress and inflammatory pathways (Kaidery et al., 2013; Turley et al., 2015). Therefore, to determine the role of Nrf2-mediated antioxidant and anti-inflammatory effects in the neuroprotective mechanism of DMF against MPTP neurotoxicity, we evaluated oxidative stress and inflammatory markers 3-NT (a marker for protein oxidation produced by reactive nitrogen species) and activated CD68-immunopositive (microglial marker) cells, respectively. Immunohistochemical analysis of coronal sections spanning the SNpc with anti-3-NT antibody showed a significant increase in 3-NT immunoreactivity in the MPTP group compared with vehicle controls (Fig. 7A). 

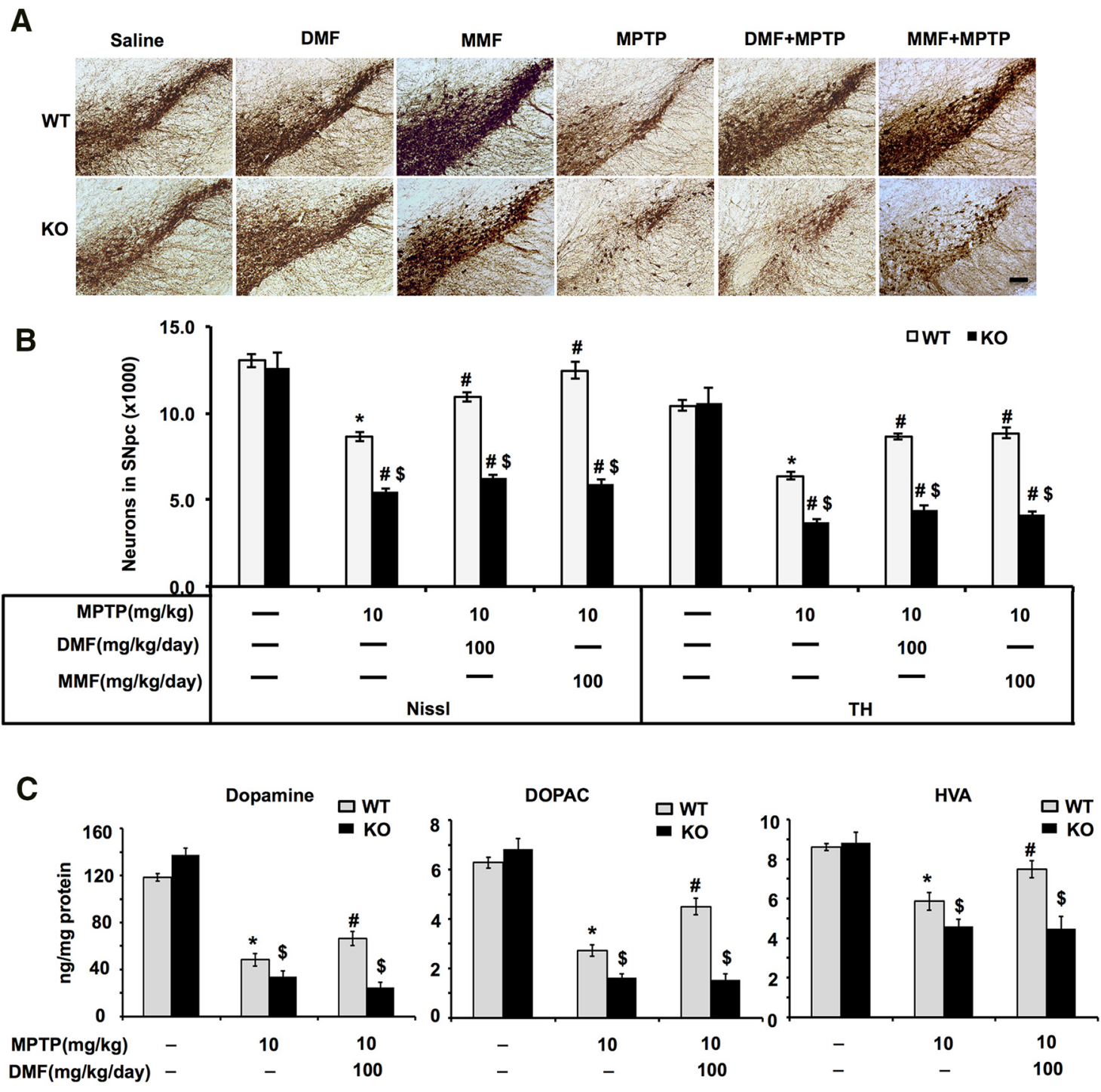

Figure 8. Nrf2-dependent neuroprotective effects of DMF and MMF against MPTP neurotoxicity. $A$, Immunohistochemical staining for TH in the SNpc of wild-type and Nrf2-K0 mice on day 7 after DMF or MMF (50 mg/kg twice a day for $7 \mathrm{~d}$ via oral gavage) treatment in the acute MPTP model. Scale bar, $100 \mu \mathrm{m}$. B. Stereological analysis of total (Nissl) and TH ${ }^{+}$neurons in the SNpc. Bars represent mean \pm SEM. ${ }^{*} p<0.05$ compared with wild-type controls; ${ }^{\#} p<0.05$ compared with wild-type MPTP; ${ }^{\$} p<0.05$ compared with K0 control ( $n=6$ mice per group). C, Striatal levels of DA and its metabolites (HVA and DOPAC) measured by HPLC analysis in wild-type and Nrf2-KO mice. Bars represent mean \pm SEM. ${ }^{*} p<0.05$ compared with saline controls; ${ }^{*} p<0.05$ compared with wild-type MPTP ( $n=6$ mice per group); ${ }^{\$} p<0.05$ compared with KO control.

Administration of DMF $\left(100 \mathrm{mg} \cdot \mathrm{kg}^{-1} \cdot \mathrm{d}^{-1}\right)$ significantly attenuated the MPTP-induced increases in 3-NT immunoreactivity in the SNpc. Quantitative analysis of 3-NT-immunoreactive area showed a marked increase in 3-NT levels in the MPTPtreated group compared with vehicle control, which was significantly reduced in the SNpc of DMF- and MPTP-treated mice (Fig. 7B). Similarly, MPTP administration significantly elevated the CD68-immunopositive activated microglia in the SNpc of the MPTP group compared with controls (Fig. 7C). Administration of DMF significantly reduced levels of MPTP-induced CD68positive activated microglia compared with MPTP-treated mice. Consistent with CD68 immunoreactivity, morphometric analysis of CD68-positive reactive microglia in the SNpc showed a profound increase in the levels of activated microglial cell counts in the MPTP-treated group compared with controls, which were markedly reduced after DMF treatment (Fig. 7D). Quantitative PCR analysis of mRNA levels for proinflammatory genes, such as tumor necrosis factor- $\alpha$, monocyte chemotactic protein 1 , and microglial activation marker Cd68, showed significant increases in the ventral midbrain after MPTP administration compared with controls (Fig. 7E). DMF treatment significantly blocked MPTP-induced increases in the mRNA levels of proinflammatory genes (Fig. 7E). In summary, these data suggest that DMFinduced neuroprotective effects against MPTP neurotoxicity are associated with marked reductions in markers of oxidative stress and inflammation.

DMF- and MMF-induced neuroprotection against MPTP toxicity is $\mathrm{Nrf} 2$ dependent

After establishing the neuroprotective effects of DMF and MMF against MPTP neurotoxicity, we next sought to determine the role of the Nrf2 pathway in their neuroprotective phenotype. To do so, we evaluated the ability of DMF and MMF to block MPTP neurotoxicity in both wild-type and Nrf2-KO mice. We administered DMF or MMF at $100 \mathrm{mg} \cdot \mathrm{kg}^{-1} \cdot \mathrm{d}^{-1} 1 \mathrm{~d}$ before MPTP and again for $5 \mathrm{~d}$ after MPTP (for details, see Materials and Meth- 

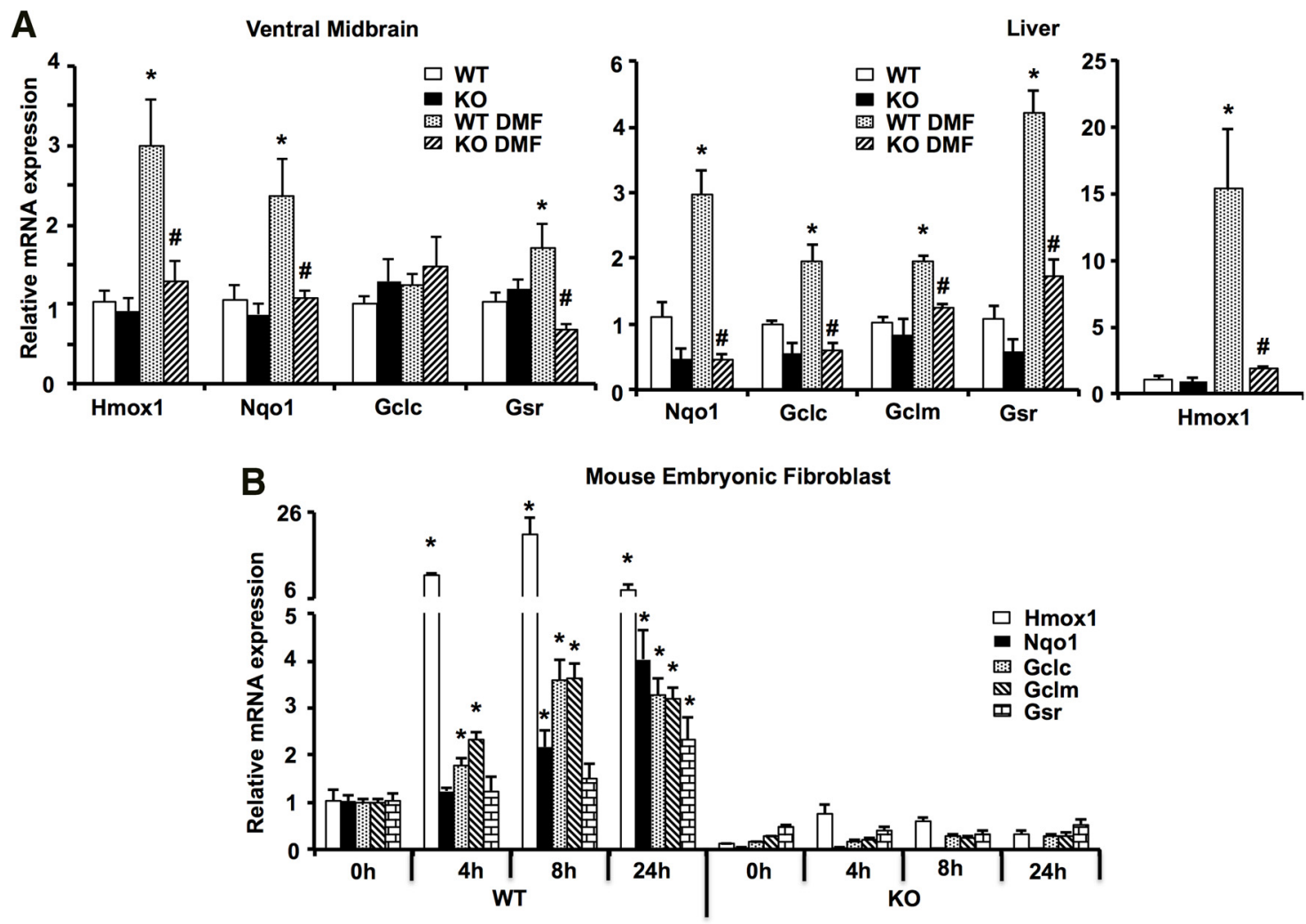

Figure 9. Selective activation of the Nrf2 pathway by DMF. A, qRT-PCR analysis showing relative mRNA levels of ARE-containing genes in the liver and ventral midbrain of wild-type and Nrf2-K0 mice $6 \mathrm{~h}$ after two doses of $50 \mathrm{mg} / \mathrm{kg} \mathrm{DMF}$ administered by oral gavage $12 \mathrm{~h}$ apart. Bars represent fold expression of mRNA relative to $\beta$-actin values depicted as mean $\pm S E M$. ${ }^{*} p<0.05$ compared with respective controls of different ARE-containing genes; ${ }^{\#} p<0.05$ compared with the respective wild-type DMF treatment group ( $n=5$ mice per group). $\boldsymbol{B}, q R T-P C R$ analysis showing relative mRNA levels of ARE-containing genes in the wild-type and Nrf2-KO MEFs after treatment with DMF $(20 \mu \mathrm{m})$ at different time points. Bars represent the mean \pm SEM of relative mRNA levels (relative to $\beta$-actin). ${ }^{*} p<0.05$ compared with $0 \mathrm{~h}$ respective controls ( $n=3$ per time point).

ods). Immunohistochemical analysis of $\mathrm{TH}$-immunopositive neurons in wild-type mice demonstrated marked reduction on day 7 after MPTP compared with wild-type controls, whereas in the Nrf2-KO mice, the loss of $\mathrm{TH}$-immunopositive neurons was more profound compared with wild-type mice treated with MPTP, suggesting increased vulnerability of Nrf2-KO mice to MPTP challenge (Fig. 8A). As anticipated, administration of DMF or MMF markedly reduced the MPTP-induced loss of THpositive neurons in the $\mathrm{SNpc}$ in the wild-type mice but failed to attenuate the neuronal loss in Nrf2-KO mice (Fig. 8A). Quantitative analysis of the $\mathrm{TH}$ - and Nissl-positive neuronal counts by unbiased stereological cell counting in the SNpc of the MPTPtreated group showed significant loss of both total (Nissl-positive neurons) and TH-positive neurons in wild-type mice and greater neuronal loss in Nrf2-KO mice compared with their respective saline controls (Fig. 8B). Administration of DMF or MMF (100 $\mathrm{mg} \cdot \mathrm{kg}^{-1} \cdot \mathrm{d}^{-1}$ ) significantly attenuated the MPTP-induced loss of total and $\mathrm{TH}$-immunopositive neuronal counts in the wildtype mice but not in Nrf2-KO mice (Fig. $8 B$ ). DMF treatment alone did not affect TH- and Nissl-positive neuronal counts in the SNpc in either wild-type or Nrf2-KO mice (data not presented). Measurement of striatal levels of catecholamines also showed a profound reduction (Fig. 8C) of DA and its metabolites (DOPAC and HVA) after MPTP treatment in wild-type mice compared with saline-injected wild-type controls. MPTP administration in Nrf2-KO mice produced a significantly greater depletion of striatal DA and its metabolites (DOPAC and HVA) compared with MPTP-treated wild-type mice (Fig. 8C). DMF treatment attenuated the MPTP-induced loss of striatal DA
(Fig. 8C) and its metabolites only in wild-type mice but not in Nrf2-KO mice. Similarly, MMF administration prevented MPTP-induced loss of striatal DA and its metabolites only in wild-type mice, not in Nrf2-KO mice (data not presented). DMF or MMF treatment alone did not affect levels of DA and its metabolites DOPAC and HVA in wild-type or Nrf2-KO mice (data not presented). These results suggest that, indeed, the neuroprotective actions of both DMF and MMF against MPTP neurotoxicity are Nrf2 dependent.

To verify that the neuroprotective mechanism of DMF or MMF against MPTP neurotoxicity is via selective activation of the Nrf2 pathway, we studied Nrf2 target genes in wild-type and Nrf2-KO mice after DMF or MMF treatment. Age-matched Nrf2-KO mice and wild-type littermates were administered DMF or MMF at $100 \mathrm{mg} \cdot \mathrm{kg}^{-1} \cdot \mathrm{d}^{-1}$ by oral gavage in two doses $12 \mathrm{~h}$ apart, and $6 \mathrm{~h}$ after the last dose, Nrf2 target genes were analyzed. Control mice from both genotypes received vehicle in the same frequency and volume as the fumarate drugs. qRT-PCR analysis showed that mRNA levels of Nrf2 target genes, such as Hmox1, Nqo1, Gclc, Gclm, and Gsr, were significantly upregulated (2- to 15 -fold) in the liver of wild-type mice after DMF compared with vehicle-treated mice. However, in the livers of Nrf2-KO mice, DMF administration failed to increase mRNA levels of these Nrf2 targeted genes (Fig. 9A). Similarly, we found elevated levels of mRNAs for Hmox1, Nqo1, and Gsr in the ventral midbrains of the DMF-treated wild-type mice but not in the Nrf2-KO mice treated with DMF (Fig. 9A). MMF administration showed similar levels of induction of the Nrf2 target gene Hmoxl as in the DMF groups in both the liver and ventral midbrain of wild-type mice 
A

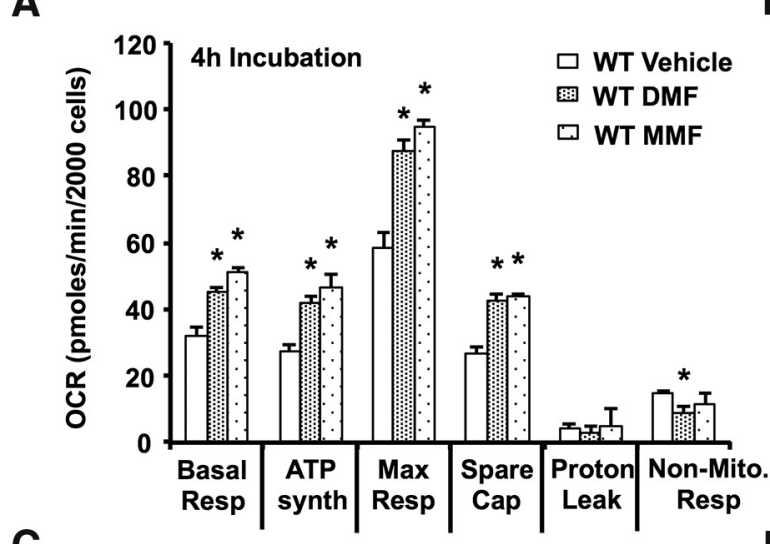

C

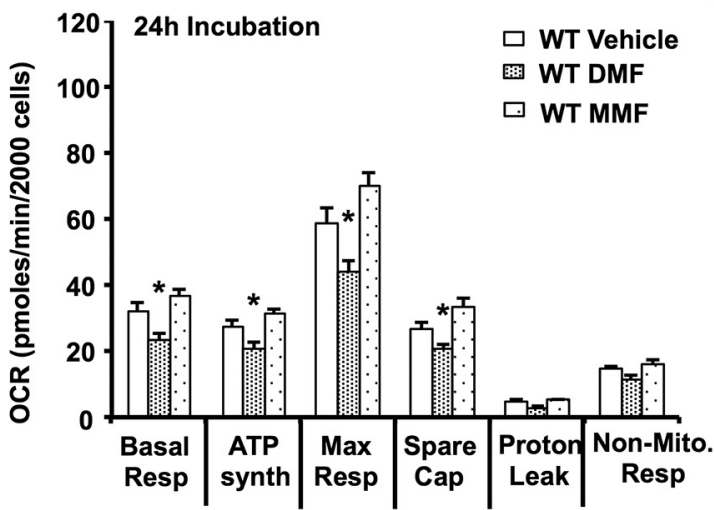

B
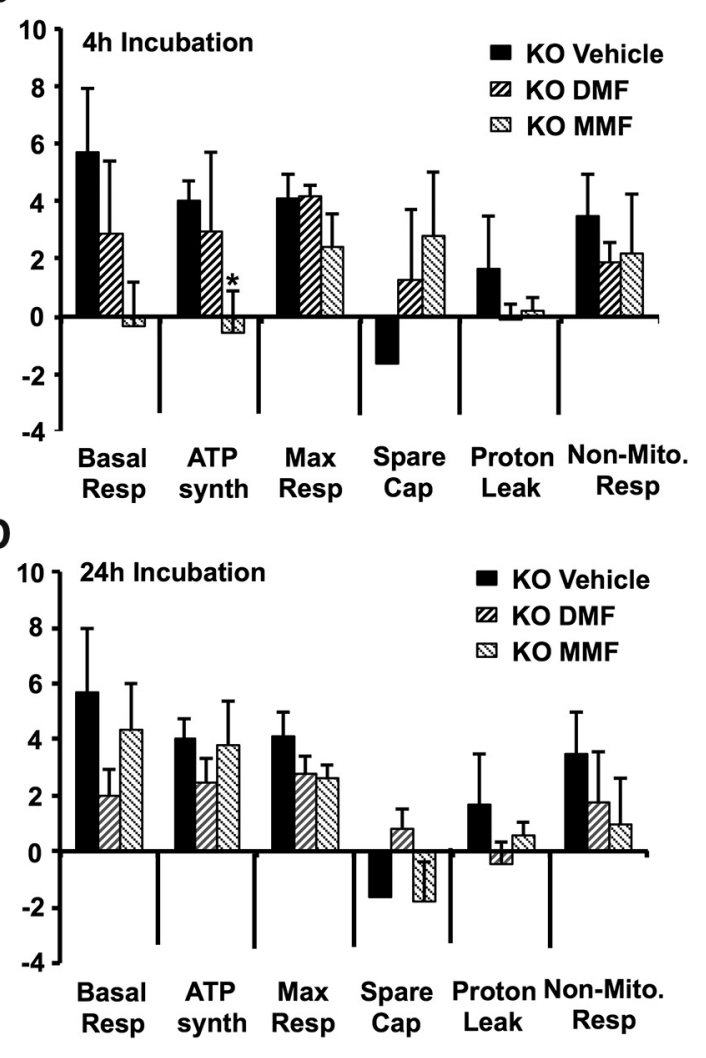

Figure 10. DMF and MMF modulate mitochondrial $0 C R$ in an Nrf2-dependent manner. $\boldsymbol{A}$, Mitochondrial 0 CR in wild-type MEFs after incubation with DMF or MMF at $20 \mu \mathrm{M}$ for $4 \mathrm{~h}(\boldsymbol{C})$ or $24 \mathrm{~h} . \boldsymbol{B}$, Mitochondrial OCR in Nrf2-KO MEFs after incubation with DMF or MMF at $20 \mu \mathrm{m}$ for $4 \mathrm{~h}$ or $24 \mathrm{~h}$ (D). Bars represent the mean \pm SEM of the 0 CR expressed in picomoles per minute per 2000 cells. ${ }^{*} p<$ 0.05 compared with vehicle controls. Each experiment was performed three times and consisted of six samples per group. Basal Resp, Basal respiration; ATP synth, ATP synthesis; Max Resp, maximum respiration; Spare Cap, spare capacity; Non-Mito. Resp, non-mitochondrial respiration.

(Fig. $5 B$ ) but not in Nrf2-KO mice (data not presented). These data essentially confirm that the observed biological effects on the Nrf2 signaling in vivo after DMF administration are mediated by MMF. To determine the time course of activation of Nrf2dependent genes, we evaluated mRNA levels in wild-type and Nrf2-KO MEFs after treatment with $20 \mu \mathrm{M}$ DMF or MMF at 0,4 , 8 , and 12 h. qRT-PCR analysis showed upregulation of mRNA levels of Hmox1, Gclc, and Gclm by $4 \mathrm{~h}$ that remained elevated up until $24 \mathrm{~h}$ after the treatment (Fig. 9B), whereas Nqo1 levels were upregulated at $8 \mathrm{~h}$ and peaked at $24 \mathrm{~h}$. Similarly, MMF also induced these Nrf2 target genes but to a lesser extent in wild-type MEFs (as in Fig. 4) when compared with DMF (data not presented). However, we did not find any induction of Nrf2 target genes in the Nrf2-KO MEFs after DMF (Fig. 9B) or MMF (data not presented) treatment. Based on these analyses in both mice and MEFs, it is evident that DMF and MMF selectively activate the Nrf2 pathway, and this effect is directly associated with the neuroprotective actions of these fumarate compounds against MPTP toxicity.

DMF and MMF differentially affect mitochondrial OCR, glycolysis, and mitochondrial biogenesis in an Nrf2dependent manner

So far, our data clearly indicate the protective action of DMF and MMF against MPTP neurotoxicity in Nrf2-expressing mice (Figs. $6,8)$. Considering that the primary target of MPTP in nigrostriatal dopaminergic neurons is mitochondria (Banerjee et al., 2009), it was of interest to examine the effects of DMF and its bioactive metabolite MMF on cellular energetics. To this end, we used Nrf2-expressing (wild-type) and Nrf2-KO cultured MEFs. To distinguish between a possible direct effect of these compounds on mitochondria (discussed below) and the expression of genes related to mitochondrial biogenesis, we selected two time points: (1) a $4 \mathrm{~h}$ incubation with $20 \mu \mathrm{M}$ DMF or MMF, when the effect of modulation of mitochondrial biogenesis gene expression is unlikely (because of the time required for protein synthesis and maturation); and (2) a $24 \mathrm{~h}$ exposure, when the effects of these compounds on gene expression and protein synthesis related to mitochondrial biogenesis can be documented (see below). Total cell incubation time was kept constant to avoid any complications stemming from cell proliferation and maturation.

Figure $10 \mathrm{~A}$ shows that a $4 \mathrm{~h}$ exposure of Nrf2-competent (wild-type) cells to either DMF or MMF significantly elevated all stages of OCR, basal respiration, phosphorylation, and maximum (uncoupled) respiration, with MMF having a somewhat greater effect than DMF (Fig. 10A). Neither compound had an effect on proton leak, whereas DMF slightly but significantly suppressed non-mitochondrial oxygen consumption. Interestingly, both compounds also significantly stimulated ECAR in Nrf2competent cells, with DMF more efficient in stimulating the rate of "glycolysis," and MMF significantly increasing the glycolytic reserve of the cells (Fig. 11A). It should be noted that ECAR reflects an acidification rate of the incubation medium, which is caused by both glycolysis and mitochondrial activity (Ferrick et al., 2008), so it is difficult to interpret these data with certainty. Nevertheless, it is safe to say that both DMF and MMF exhibited 
A

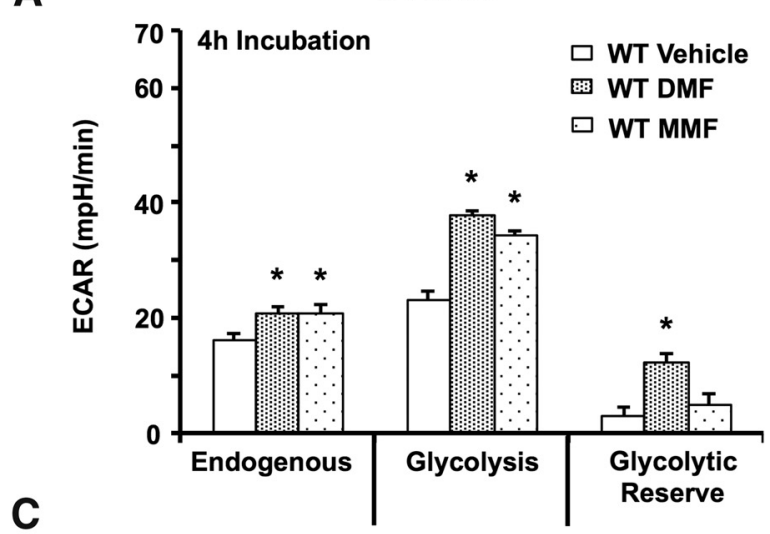

B
Nrf2 KO MEFs

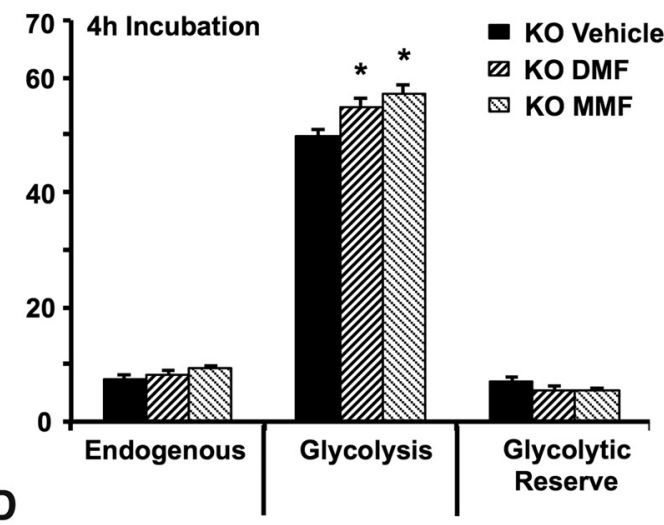

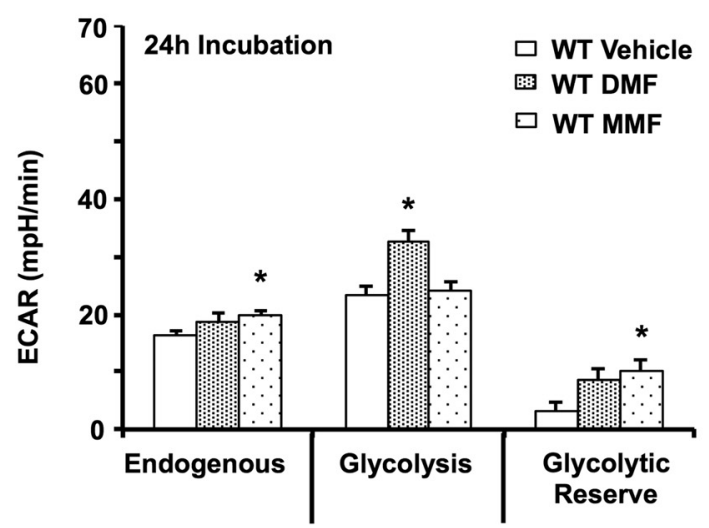

Figure 11. Modulation of ECAR by DMF and MMF in an Nrf2-dependent manner. $\boldsymbol{A}$, ECAR in wild-type MEFs after incubation with DMF or MMF at $20 \mu \mathrm{M}$ for $4 \mathrm{~h}$ or $24 \mathrm{~h}$ ( $\boldsymbol{C}$ ). $\boldsymbol{B}$, ECAR in Nrf2-KO MEFs after incubation with DMF or MMF at $20 \mu \mathrm{m}$ for $4 \mathrm{~h}$ or $24 \mathrm{~h}(\boldsymbol{D})$. Bars represent the mean \pm SEM ECAR expressed in mpH per minute. ${ }^{*} p<0.05$ compared with vehicle controls $(n=6)$. Each experiment was performed three times and consisted of six samples per group.

pronounced stimulating effects on cellular utilization of oxygen and (apparently) glucose consumption in Nrf2-competent cells with a $4 \mathrm{~h}$ exposure. As will be discussed in more detail below, this stimulation is not compatible with an uncoupling mechanism of action of these compounds but rather likely a stimulation of substrate supply to mitochondria, or a switch from oxidizing $\mathrm{NADH}$-dependent substrates to FADH-dependent substrates.

Nevertheless, the effects of DMF and MMF on OCR and ECAR were clearly dependent on the incubation time. Whereas the MMF effect on OCR (Fig. 10C) and glycolysis rate (Fig. 11C) returned to baseline after $24 \mathrm{~h}$ incubation, DMF significantly suppressed all OCR parameters (Fig. 10C), while still stimulating the glycolysis rate (Fig. 11C) in Nrf2-competent cells. Conversely, glycolytic reserve was significantly increased by MMF only with the longer incubation time (Fig. 11C). However, $50 \mu \mathrm{M}$ DMF, which depleted cellular GSH and reduced cell viability (Fig. 1), inhibited all the measured parameters for both OCR and ECAR at $4 \mathrm{~h}$, whereas $50 \mu \mathrm{M}$ MMF significantly increased both OCR rates and glycolysis at this time (data not presented). The worsening effect of DMF on parameters of bioenergetics has been documented in $\mathrm{CD}^{+}{ }^{+}$lymphocytes of patients treated with DMF who developed progressive multifocal leukoencephalopathy (PML; Haghikia et al., 2011). This can be further explained by the alkylating properties of DMF clearly demonstrated in our work with respect to GSH, resulting in cytotoxicity (Fig. 1). It is safe to assume that any compound capable of a direct alkylation of GSH will be also be capable of reacting with some critical sulfhydryl (SH) groups of metabolic and regulatory proteins. It is well known that various SH-targeting alkylating agents negatively af- fect various mitochondrial functions, including (but not limited to) inhibition of ATPase (Yagi and Hatefi, 1987), protein import into mitochondria (von Stedingk et al., 1997), bioenergetics and structural integrity ( Lê-Quôc and Lê-Quôc, 1985), and even resulting in depletion of mtDNA (Eizirik et al., 1991). Moreover, by depleting GSH, DMF forces cells to regenerate this antioxidant by de novo biosynthesis, which represents a metabolic burden. Therefore, temporal deleterious effects of DMF on cellular bioenergetics are not surprising but rather expected.

Unfortunately, OCR measurements with $\mathrm{Nrf2}-\mathrm{KO}$ cells were not successful at neither the 4 or $24 \mathrm{~h}$ incubation because of their extremely low respiration activity (Fig. $10 \mathrm{~B}, \mathrm{D}$ ). None of the differences presented in Figure 10, $B$ and $D$, are significant, despite several repeated experiments. Increasing cell-plating density three times did not resolve the issue, because the OCR was still very low and the differences were not significant (data not presented), so further attempts were deemed impractical. Of note, this observation is not unique to our cell culture; similar issues with Nrf2-KO cells were noted previously (Holmström et al., 2013; Foresti et al., 2015). Conversely, Nrf2-KO cells exhibited much higher glycolytic activity than control cells, and this was subtly but significantly stimulated by both DMF and MMF at $4 \mathrm{~h}$ of incubation (Fig. 11B). Glycolysis remained elevated in these cells at $24 \mathrm{~h}$, but at that time, DMF somewhat suppressed glycolysis, whereas MMF again had no significant effect (Fig. 11D).

Thus, it appeared that both DMF and MMF exhibited distinct short- and long-term effects on cellular energetics. To further clarify whether these effects have a mitochondrial connection, we examined the biogenesis of mitochondria by assessing the 
A

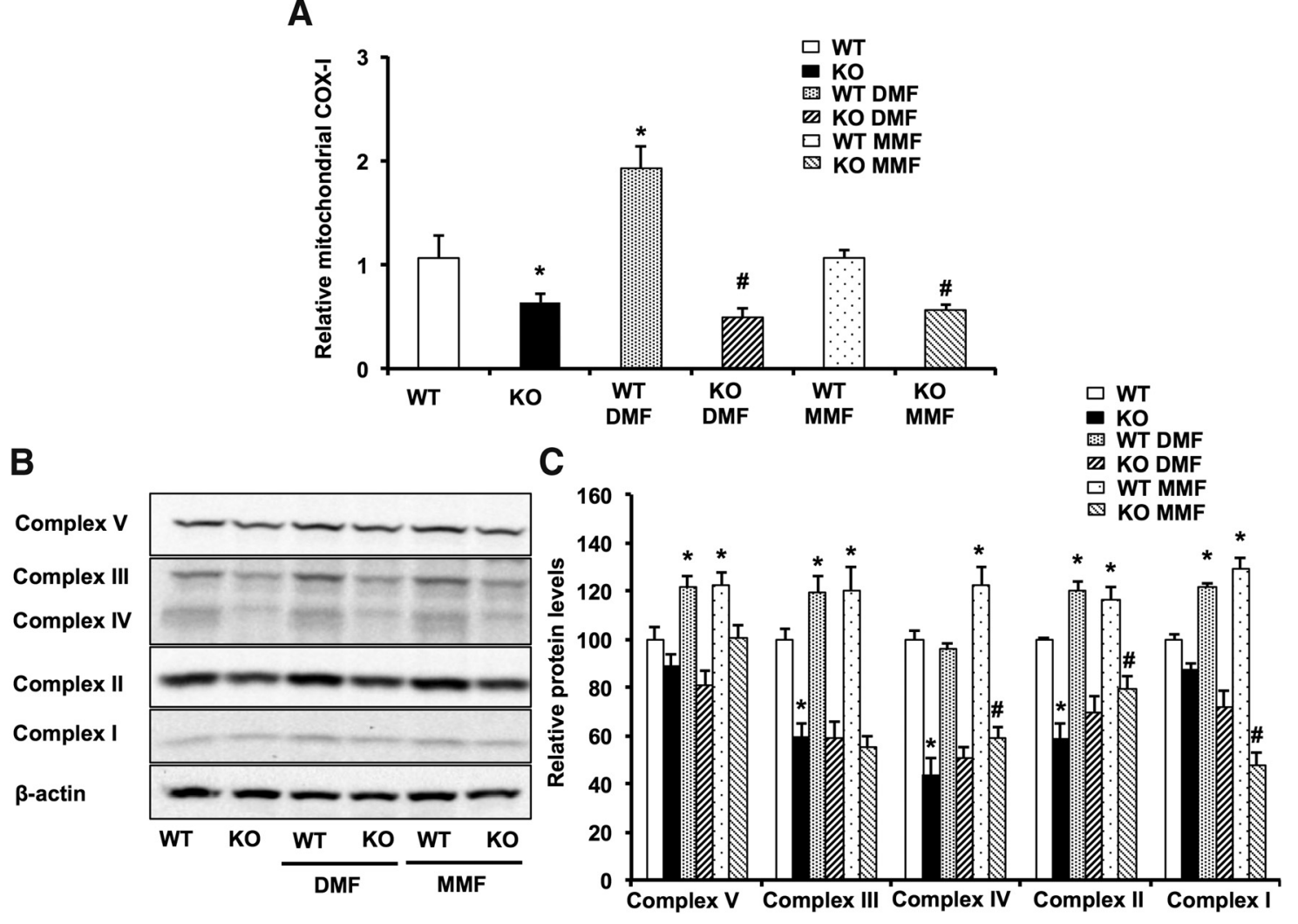

Figure 12. DMF and MMF increase mtDNA copy number and OXPHOS content in an Nrf2-dependent manner. $A$, Relative levels of the mtDNA variant of cytochrome coxidase 1 gene were assessed in DMF-treated $(20 \mu \mathrm{M})$ and MMF-treated $(20 \mu \mathrm{M})$ wild-type and Nrf2-KO MEFs to determine the relative mitochondrial copy number. Cells were treated for $24 \mathrm{~h}$, and mRNA levels were measured by qRT-PCR analysis. Bars represent the mean \pm SEM of mRNA levels (relative to $\beta$-actin). ${ }^{*} p<0.05$ compared with wild-type vehicle control; ${ }^{*} p<0.05$ compared with Nrf2-K0 vehicle control $(n=3)$. Immunoblot analysis $(\boldsymbol{B})$ and densitometry analysis $(\boldsymbol{C})$ of different subunits of complexes involved in mitochondrial electron transport chain after DMF $(20 \mu \mathrm{M})$ or MMF (20 $\mu \mathrm{M})$ treatment for $24 \mathrm{~h}$ in MEFs. Bars represent percentage control values depicted as mean \pm SEM. ${ }^{*} p<0.05$ compared with wild-type vehicle control; ${ }^{\#} p<0.05$ compared with respective Nrf2-K0 vehicle control $(n=5)$. mitochondrial COX-I, Mitochondrial cytochrome c oxidase I.

amount of mtDNA and the expression of key energy-related mitochondrial genes and proteins. We found that Nrf2-KO cells have a lower mtDNA content than wild-type cells. Nrf2-KO cells were found to have lower levels of key proteins, including respiratory chain complexes II (succinate dehydrogenase), III (bc complex), and IV (cytochrome oxidase), than Nrf2-competent cells (Fig. 12B,C). DMF significantly increased the amount of mtDNA at 24 h but only in Nrf2-competent cells, with MMF having no detectable effect (Fig. 12A). However, with respect to protein levels, both DMF and MMF increased the amount of ATPase (complex V), complex III, complex II, and complex I in Nrf2-competent cells after $24 \mathrm{~h}$ exposure with approximately equal efficiency, whereas cytochrome $c$ oxidase (complex IV) was only increased by MMF treatment (Fig. 12C). Altogether, these data strongly indicate that both DMF and MMF stimulated mitochondrial biogenesis and increased mitochondria oxidative capacity by means of de novo synthesis of mitochondrial respiratory chain proteins, although with some differences observed for the two compounds that cannot be rationalized with the current set of data. Furthermore, the effects of DMF and MMF (Fig. 13) on the expression of genes that are involved in mtDNA maintenance/stability and transcription (Ssbp1, Terf, Terf3, TBf1m, Tbf2m, Tfam, Polg2, Polrmt, and Peo1) and respiratory chain (Nd1, Nd2, Nd5, Nd6, Cytob, and Cox3) strongly support the notion that both DMF and MMF stimulate the biogenesis of mitochondria, despite the different magnitude of their effects on mtDNA maintenance gene expression (Fig. 13), cellular GSH levels (Fig. 1C), and Nrf2 activation (Fig. 2A).

\section{Discussion}

The clinical efficacy of fumaric acid esters for the treatment of MS has ignited considerable interest in the potential neuroprotective actions of DMF and MMF in a wide range of disorders (Ruggieri et al., 2014). The antioxidant, cytoprotective, and immunomodulatory actions of DMF and MMF have been mainly attributed to their ability to activate the Nrf2 pathway (Dubey et al., 2015). However, the unique and differential effects of DMF and its metabolite MMF on Nrf2 activity and its potential relationship with therapeutic effects in vivo remain elusive. Here for the first time, we compared therapeutic efficacy of both DMF and MMF in the MPTP-mouse model of PD and studied potential mechanisms of Nrf2 activation and its relationship with downstream neuroprotective events.

Both DMF and MMF activate the Nrf2 pathway by distinct S-alkylating properties. Our comparison of DMF and MMF with respect to nonspecific modification of GSH and to Neh2-luc reporter activation indirectly suggested that MMF could work more specifically with respect to Keap 1 thiols. This conclusion is supported by recent data on Keap1 thiol modification in vitro in HEK293 cells using DMF and monoethylfumarate (Brennan et al., 2015). Monoethylfumarate preferentially modified Cys151, whereas DMF modified many active Keap1 cysteines. It is possible that MMF, similar to monoethylfumarate, is specific for a key thiol in Keap1. The complete quenching of Neh2-luc reporter activation by DMF in the presence of high concentrations of GSH is the best illustration of the low specificity of DMF for 

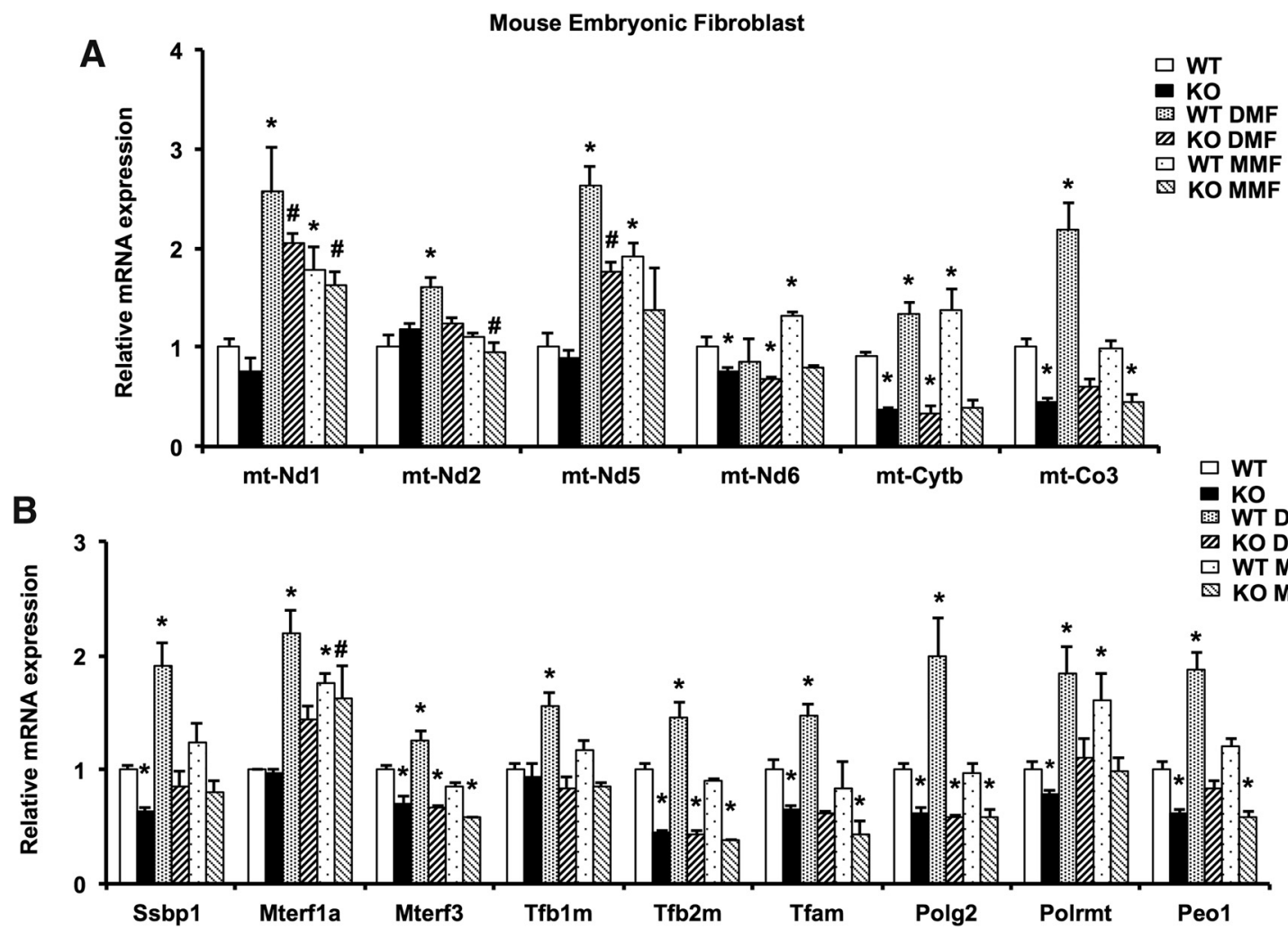

Figure 13. DMF and MMF induce mitochondrial biogenesis in an Nrf2-dependent manner. $A, B$, Relative mRNA levels of mitochondrial biogenesis genes in DMF-treated (20 $\mu \mathrm{M}$ ) or MMF-treated $(20 \mu \mathrm{M})$ wild-type and Nrf2-KO MEFs. Cells were treated for $24 \mathrm{~h}$, and mRNA levels were measured by qRT-PCR analysis. Bars represent the mean \pm SEM of mRNA levels (relative to $\beta$-actin). ${ }^{*} p<$ 0.05 compared with wild-type vehicle control; $\# p<0.05$ compared with respective K0 vehicle control $(n=3)$. $\mathrm{mt}-\mathrm{Nd1}$, mitochondrial-encoded NADH dehydrogenase 1 ; $\mathrm{mt}-\mathrm{Nd2}$, mitochondrialencoded NADH dehydrogenase 2; mt-Nd5, mitochondrial-encoded NADH:ubiquinone oxidoreductase core subunit 5; mt-Nd6, mitochondrial-encoded NADH:ubiquinone oxidoreductase core subunit 6; mt-Cytb, mitochondrial cytochrome b; mtC03, mitochondrial cytochrome c oxidase subunit III; Ssbp1, single-stranded DNA binding protein 1, mitochondrial; Mterf1a, mitochondrial transcription termination factor 1a; Mterf3, mitochondrial transcription termination factor 3; Tfb1m, transcription factor B1, mitochondrial; Tfb2m, transcription factor B2, mitochondrial; Tfam, transcription factor A, mitochondrial; Polg2, polymerase (DNA directed), $\gamma 2$, accessory subunit; Polrmt, polymerase (RNA) mitochondrial (DNA directed); Peo1, progressive external ophthalmoplegia 1 (Twinkle protein, mitochondrial).

Keap1 thiols, whereas GSH has no effect on MMF-induced Neh2-luc reporter activation. Intracellular nonspecific quenching of DMF by GSH was demonstrated: the reported drop in GSH after addition of DMF was $\sim 70-75 \%$, whereas monoethylfumarate caused no measurable drop in intracellular GSH levels (Brennan et al., 2015). We also found that in vitro DMF induced Nrf2 genes more potently than MMF at comparable doses (Fig. 4), consistent with previous reports (Albrecht et al., 2012; Scannevin et al., 2012; Gillard et al., 2015). Moreover, activation of Nrf2 by DMF but not MMF was accompanied by a dose-dependent depletion of GSH and cytotoxicity, with DMF exerting no effect on GSH levels and cell viability at lower doses. Consistent with our findings, some studies have documented GSH depletion by DMF in vitro (Ghashghaeinia et al., 2010; Lin et al., 2011; Xie et al., 2015), whereas others showed that GSH levels recover after a transient depletion acutely after DMF treatment (Brennan et al., 2015).

Surprisingly, in vivo comparisons between DMF and MMF did not reveal significant differences in Nrf2 activity. After oral intake, DMF is rapidly hydrolyzed by esterases to its bioactive metabolite MMF: the half-life of DMF is $\sim 12 \mathrm{~min}$, whereas that of MMF is $36 \mathrm{~h}$. The highest concentration of MMF in human serum was measured 5-6 h after oral intake (Litjens et al., 2004; Dubey et al., 2015). Our pharmacokinetic studies in mice only detected MMF and not DMF, with peak concentrations at $6 \mathrm{~h}$ after oral administration (Fig. 5A). This suggests that both com- pounds should activate the Nrf2 pathway identically in vivo, likely mediated by MMF as a result of rapid hydrolysis of DMF (Dibbert et al., 2013). However, there is evidence that not all pharmacological effects of DMF are exerted by MMF and that DMF may have unique pharmacological properties and thus should not be considered a prodrug of MMF (Schmidt et al., 2007; RostamiYazdi et al., 2009; Dibbert et al., 2013). Given the equipotent therapeutic effect of both DMF and MMF against MPTP neurotoxicity, it seems unlikely that DMF caused GSH depletion in vivo because GSH is crucial for the survival of DA neurons (Chinta et al., 2007) and doses of DMF that protected against MPTP in our studies did not affect GSH levels in vivo (Ghashghaeinia et al., 2010). The most compelling evidence for Nrf2 pathway activation by DMF and MMF in ameliorating MPTP neurotoxicity came from our studies using wild-type and $\mathrm{Nrf2}-\mathrm{KO}$ mice. These effects directly correlated with the ability of DMF and MMF to induce selective activation of Nrf2/ARE genes in the wild-type but not Nrf2-KO mice. Our results are consistent with the demonstration of efficacy of DMF in a 6-OHDA model of PD (Jing et al., 2015) and the fact that both DMF and its bioactive metabolite MMF block against neurodegeneration in an Nrf2-dependent manner (Fig. 8; Cho et al., 2015). Additional evidence of Nrf2 as a potential target mediating neuroprotection was further confirmed by the inability of either DMF or MMF to protect against $\mathrm{MPP}^{+}$toxicity in vitro when the activity of HO-1, an Nrf2 target gene, was inhibited (Fig. 3). 


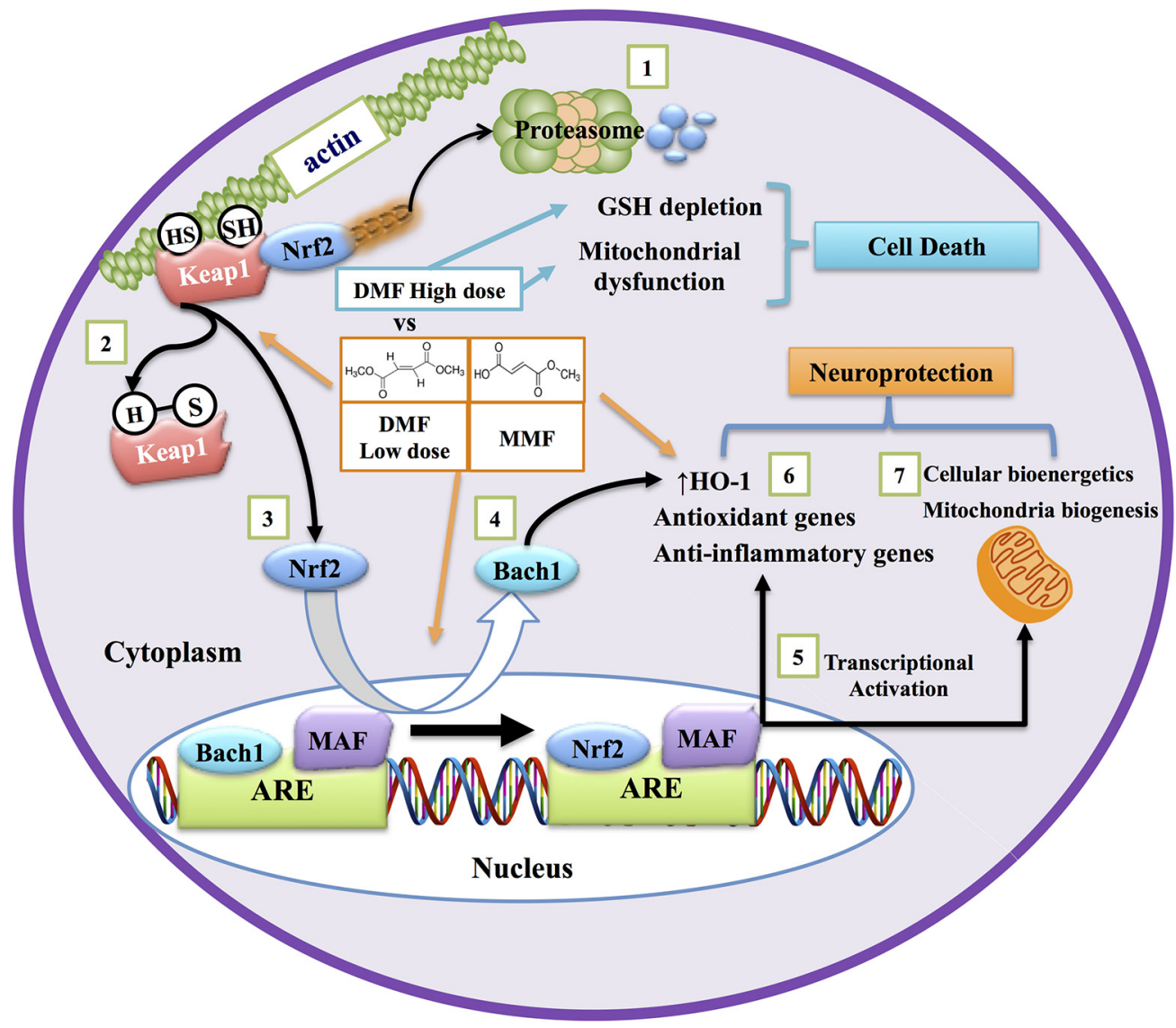

Figure 14. Mechanism of Nrf2 activation by DMF and MMF and its role in neuroprotection. DMF and MMF differentially activate the Nrf2/ARE pathway to modulate the antioxidant, antiinflammatory, and mitochondrial biosynthetic machinery. 1, Under basal conditions, Nrf2 is sequestered in the cytoplasm through its binding to its cytoplasmic inhibitor Keap1, which promotes Nrf2 degradation via a ubiquitin proteasome pathway. 2 , In the presence of electrophilic agents such as DMF and MMF, the cysteine residues on Keap1 are modified as a result of an alkylation or reduction process, which in turns prevents the ubiquitin-dependent proteasomal degradation of Nrf2. Both DMF and MMF in our study have been shown to possess strong alkylation properties toward thiol groups present on GSH; this characteristic might explain their ability to disrupt the Keap1-Nrf2 interaction by alkylating the cysteine residues on Keap1, leading to nuclear translocation of Nrf2. 3, 4, The Nrf2 pathway is kept in check normally by Bach1, which interacts with small Maf proteins in the nucleus and acts as a repressor of Nrf2-induced ARE-containing gene activation. Once inside the nucleus, Nrf2 binds to the ARE sites of the ARE-containing genes after the export of Bach1 from the nucleus to the cytoplasm. 5, After the export of Bach1 from the nucleus, Nrf2 complexes with small Maf proteins, induces ARE activation, and upregulates a battery of genes involved in antioxidant and anti-inflammatory responses. 6, Both DMF and MMF demonstrate activation of the Nrf2 pathway, although differentially. 7, In our study, we also found that DMF and MMF mediated mitochondrial biogenesis in an Nrf2-dependent manner via an unknown mechanism, accompanied by enhanced cellular bioenergetics to render neuroprotection. Nrf2 activation by DMF, but not MMF, was associated with depletion of GSH, decreased cell viability, and inhibition of mitochondrial oxygen consumption and glycolysis rates in a dose-dependent manner, whereas MMF increased these activities in vitro.

Additional evidence of the involvement of the Nrf2 pathway in neuroprotection came from the Seahorse data with DMF/MMF-treated wild-type and Nrf2-KO cells. These yielded three major findings. First is a failure of Nrf2-KO cells to respire, with or without treatment with DMF/MMF (Fig. $10 B, D)$. This result is in line with a previous report that mitochondria in Nrf2-KO cells are depolarized and exhibit impaired respiration and an increased glycolytic ATP production rate (Holmström et al., 2013). However, because protein levels and in vitro activities of the respiratory complexes are not affected by Nrf2 deletion, Holmström et al. concluded that respiration of Nrf2-KO cells was impaired because of insufficient substrate supply to mitochondria. Noting that glycolytic (ECAR) rates were elevated in Nrf2-KO cells in our experiments, we think it is unlikely that glycolysis-derived pyruvate was in short supply in Nrf2-KO cells. Rather, the amount/ activity of substrate transporters (e.g., mitochondrial pyruvate carrier) may be depressed in Nrf2-KO cells. However, this idea requires additional focused studies.

We also observed similarities between the effects of DMF and MMF on OCR of Nrf2-competent cells after a $4 \mathrm{~h}$ exposure and significant differences after a $24 \mathrm{~h}$ exposure. A 4 h exposure to either DMF or MMF significantly elevated all stages of OCR in wild-type cells, including basal, phosphorylating, and maximum respiration, with MMF exhibiting a greater effect than DMF (Fig. 10A). Both compounds were without effect on proton leak. These data cannot be explained by "uncoupling" or de novo protein synthesis. However, elevated OCR rates could stem from a change in the concentration of tricarboxylic acid cycle (TCA) substrates in the cell cytosol, especially those limiting TCA activity, such as malate and succinate, or a switch from oxidizing NAD-dependent substrates (pyruvate, in this case) to FADdependent substrates (succinate). This theoretical possibility may be rationalized assuming the following scenario: DMF and MMF accumulate in the cell cytosol because of their demethylation to fumarate and further conversion to malate by ubiquitous fumarases. In turn, malate, after conversion to oxaloacetate, could boost the oxidation of pyruvate and the overall TCA activity. If one assumes that substrate supply limitation is restricting the OCR, an influx of extra-mitochondrial malate should stimulate OCR. However, this is a hypothetical scenario requiring additional investigation. A threefold to fourfold increase in intra- 
cellular levels of fumarate, succinate, and malate was shown after a $24 \mathrm{~h} \mathrm{DMF}$ treatment (Huang et al., 2015). This result does not contradict our finding that a $24 \mathrm{~h}$ DMF treatment suppressed mitochondrial OCR, because this suppression should result in an inability of mitochondria to oxidize TCA substrates.

Finally, we found that, in wild-type cells, DMF significantly increased the amount of mtDNA, whereas both DMF and MMF increased the transcription levels of genes that are involved in mtDNA maintenance/stability and transcription and respiratory chain, as well as a subtle but significant increase in the abundance of key bioenergetics-related proteins, such as ATPase, complex IV, complex III, complex II, and complex I. This result strongly suggests that the mechanism of the protective action of DMF and MMF involves the Nrf2 signaling cascade and DMF/MMF stimulation of mitochondrial biogenesis.

In conclusion, there are numerous therapeutic options for motor and non-motor symptoms of PD. However, there are no therapies yet with proven neuroprotective or disease-slowing properties (Olanow et al., 2008). Our data suggest that targeting neuroinflammation, mitochondrial dysfunction, and oxidative stress by fumarates in early PD is ideal (Taylor et al., 2013; Banerjee et al., 2015), although the high alkylating ability of DMF is reported to induce a drop in white blood cell counts (Spencer et al., 2015), which may lead to PML and death in some cases (van Kester et al., 2015). One of the approaches to minimize the harm from DMF is the use of capsulated forms to provide a slow release of the drug. Additionally, many pharmaceutical companies (http://investor.xenoport.com/releasedetail.cfm?releaseid=931600; https: $/ / \mathrm{cmsc}$.confex.com $/ \mathrm{cmsc} /$ 2015/webprogram/Paper3544.html) are developing novel MMF prodrugs that are well tolerated with minimal side effects when compared with DMF. Based on our results reported here, we believe that MMF is a more promising therapeutic candidate than DMF for PD (Fig. 14). To further explore the neuroprotective potential of fumarates, additional studies in genetic and chronic preclinical models of PD are warranted. These may provide additional insights into how fumarates can be used most effectively for future clinical trials for the prevention and treatment of human PD.

\section{References}

Albrecht P, Bouchachia I, Goebels N, Henke N, Hofstetter HH, Issberner A, Kovacs Z, Lewerenz J, Lisak D, Maher P, Mausberg AK, Quasthoff K, Zimmermann C, Hartung HP, Methner A (2012) Effects of dimethyl fumarate on neuroprotection and immunomodulation. J Neuroinflammation 9:163. CrossRef Medline

Banerjee R, Starkov AA, Beal MF, Thomas B (2009) Mitochondrial dysfunction in the limelight of Parkinson's disease pathogenesis. Biochim Biophys Acta 1792:651-663. CrossRef Medline

Banerjee R, Ammal Kaidery N, Thomas B (2015) Oxidative stress in Parkinson's disease: role in neurodegeneration and targets for therapeutics. ACS Symposium Series. CrossRef

Blesa J, Przedborski S (2014) Parkinson's disease: animal models and dopaminergic cell vulnerability. Front Neuroanat 8:155. CrossRef Medline

Brennan MS, Matos MF, Li B, Hronowski X, Gao B, Juhasz P, Rhodes KJ, Scannevin RH (2015) Dimethyl fumarate and monoethyl fumarate exhibit differential effects on KEAP1, NRF2 activation, and glutathione depletion in vitro. PLoS One 10:e0120254. CrossRef Medline

Calabrese V, Cornelius C, Dinkova-Kostova AT, Calabrese EJ, Mattson MP (2010) Cellular stress responses, the hormesis paradigm, and vitagenes: novel targets for therapeutic intervention in neurodegenerative disorders. Antioxid Redox Signal 13:1763-1811. CrossRef Medline

Calkins MJ, Johnson DA, Townsend JA, Vargas MR, Dowell JA, Williamson TP, Kraft AD, Lee JM, Li J, Johnson JA (2009) The Nrf2/ARE pathway as a potential therapeutic target in neurodegenerative disease. Antioxid Redox Signal 11:497-508. CrossRef Medline

Chinta SJ, Kumar MJ, Hsu M, Rajagopalan S, Kaur D, Rane A, Nicholls DG, Choi J, Andersen JK (2007) Inducible alterations of glutathione levels in adult dopaminergic midbrain neurons result in nigrostriatal degeneration. J Neurosci 27:13997-14006. CrossRef Medline

Cho H, Hartsock MJ, Xu Z, He M, Duh EJ (2015) Monomethyl fumarate promotes Nrf2-dependent neuroprotection in retinal ischemia-reperfusion. J Neuroinflammation 12:239. CrossRef Medline

Dibbert S, Clement B, Skak-Nielsen T, Mrowietz U, Rostami-Yazdi M (2013) Detection of fumarate-glutathione adducts in the portal vein blood of rats: evidence for rapid dimethylfumarate metabolism. Arch Dermatol Res 305:447-451. CrossRef Medline

Dinkova-Kostova AT, Baird L, Holmström KM, Meyer CJ, Abramov AY (2015) The spatiotemporal regulation of the Keap1-Nrf2 pathway and its importance in cellular bioenergetics. Biochem Soc Trans 43:602-610. CrossRef Medline

Dubey D, Kieseier BC, Hartung HP, Hemmer B, Warnke C, Menge T, MillerLittle WA, Stuve O (2015) Dimethyl fumarate in relapsing-remitting multiple sclerosis: rationale, mechanisms of action, pharmacokinetics, efficacy and safety. Expert Rev Neurother 15:339-346. CrossRef Medline

Dumont M, Stack C, Elipenahli C, Jainuddin S, Gerges M, Starkova N, Calingasan NY, Yang L, Tampellini D, Starkov AA, Chan RB, Di Paolo G, Pujol A, Beal MF (2012) Bezafibrate administration improves behavioral deficits and tau pathology in P301S mice. Hum Mol Genet 21:50915105. CrossRef Medline

Eizirik DL, Sandler S, Ahnström G, Welsh M (1991) Exposure of pancreatic islets to different alkylating agents decreases mitochondrial DNA content but only streptozotocin induces long-lasting functional impairment of B-cells. Biochem Pharmacol 42:2275-2282. CrossRef Medline

Ellrichmann G, Petrasch-Parwez E, Lee DH, Reick C, Arning L, Saft C, Gold R, Linker RA (2011) Efficacy of fumaric acid esters in the R6/2 and YAC128 models of Huntington's disease. PLoS One 6:e16172. CrossRef Medline

Ferrick DA, Neilson A, Beeson C (2008) Advances in measuring cellular bioenergetics using extracellular flux. Drug Discov Today 13:268-274. CrossRef Medline

Foresti R, Bucolo C, Platania CM, Drago F, Dubois-Randé JL, Motterlini R (2015) Nrf2 activators modulate oxidative stress responses and bioenergetic profiles of human retinal epithelial cells cultured in normal or high glucose conditions. Pharmacol Res 99:296-307. CrossRef Medline

Fox RJ, Miller DH, Phillips JT, Hutchinson M, Havrdova E, Kita M, Yang M, Raghupathi K, Novas M, Sweetser MT, Viglietta V, Dawson KT (2012) Placebo-controlled phase 3 study of oral BG-12 or glatiramer in multiple sclerosis. N Engl J Med 367:1087-1097. CrossRef Medline

Gennari O, Montesano D, Salzano A, Albrizio S, Grumetto L (2011) Determination of dimethyl fumarate in desiccant and antimould sachets by reversed-phase liquid chromatography. Biomed Chromatogr 25: 1315-1318. CrossRef Medline

Ghashghaeinia M, Bobbala D, Wieder T, Koka S, Brück J, Fehrenbacher B, Röcken M, Schaller M, Lang F, Ghoreschi K (2010) Targeting glutathione by dimethylfumarate protects against experimental malaria by enhancing erythrocyte cell membrane scrambling. Am J Physiol Cell Physiol 299:C791-C804. CrossRef Medline

Gillard GO, Collette B, Anderson J, Chao J, Scannevin RH, Huss DJ, Fontenot JD (2015) DMF, but not other fumarates, inhibits NF-kappaB activity in vitro in an Nrf2-independent manner. J Neuroimmunol 283:74-85. CrossRef Medline

Gold R, Kappos L, Arnold DL, Bar-Or A, Giovannoni G, Selmaj K, Tornatore C, Sweetser MT, Yang M, Sheikh SI, Dawson KT (2012) Placebocontrolled phase 3 study of oral BG-12 for relapsing multiple sclerosis. N Engl J Med 367:1098-1107. CrossRef Medline

Haghikia A, Perrech M, Pula B, Ruhrmann S, Potthoff A, Brockmeyer NH, Goelz S, Wiendl H, Lindå H, Ziemssen T, Baranzini SE, Käll TB, Bengel D, Olsson T, Gold R, Chan A (2011) Functional energetics of CD4+cellular immunity in monoclonal antibody-associated progressive multifocal leukoencephalopathy in autoimmune disorders. PLoS One 6:e18506. CrossRef Medline

Holmström KM, Baird L, Zhang Y, Hargreaves I, Chalasani A, Land JM, Stanyer L, Yamamoto M, Dinkova-Kostova AT, Abramov AY (2013) Nrf2 impacts cellular bioenergetics by controlling substrate availability for mitochondrial respiration. Biol Open 2:761-770. CrossRef Medline

Huang H, Taraboletti A, Shriver LP (2015) Dimethyl fumarate modulates antioxidant and lipid metabolism in oligodendrocytes. Redox Biol 5: 169-175. CrossRef Medline

Igarashi K, Sun J (2006) The heme-Bachl pathway in the regulation of oxi- 
dative stress response and erythroid differentiation. Antioxid Redox Signal 8:107-118. CrossRef Medline

Iniaghe LO, Krafft PR, Klebe DW, Omogbai EK, Zhang JH, Tang J (2015) Dimethyl fumarate confers neuroprotection by casein kinase 2 phosphorylation of Nrf2 in murine intracerebral hemorrhage. Neurobiol Dis 82: 349-358. CrossRef Medline

Itoh K, Chiba T, Takahashi S, Ishii T, Igarashi K, Katoh Y, Oyake T, Hayashi N, Satoh K, Hatayama I, Yamamoto M, Nabeshima Y (1997) An Nrf2/ small Maf heterodimer mediates the induction of phase II detoxifying enzyme genes through antioxidant response elements. Biochem Biophys Res Commun 236:313-322. CrossRef Medline

Jing X, Shi H, Zhang C, Ren M, Han M, Wei X, Zhang X, Lou H (2015) Dimethyl fumarate attenuates 6-OHDA-induced neurotoxicity in SHSY5Y cells and in animal model of Parkinson's disease by enhancing Nrf2 activity. Neuroscience 286:131-140. CrossRef Medline

Kaidery NA, Banerjee R, Yang L, Smirnova NA, Hushpulian DM, Liby KT, Williams CR, Yamamoto M, Kensler TW, Ratan RR, Sporn MB, Beal MF, Gazaryan IG, Thomas B (2013) Targeting Nrf2-mediated gene transcription by extremely potent synthetic triterpenoids attenuate dopaminergic neurotoxicity in the MPTP mouse model of Parkinson's disease. Antioxid Redox Signal 18:139-157. CrossRef Medline

Kensler TW, Wakabayashi N, Biswal S (2007) Cell survival responses to environmental stresses via the Keap1-Nrf2-ARE pathway. Annu Rev Pharmacol Toxicol 47:89-116. CrossRef Medline

Lê-Quôc K, Lê-Quôc D (1985) Crucial role of sulfhydryl groups in the mitochondrial inner membrane structure. J Biol Chem 260:7422-7428. Medline

Lin SX, Lisi L, Dello Russo C, Polak PE, Sharp A, Weinberg G, Kalinin S, Feinstein DL (2011) The anti-inflammatory effects of dimethyl fumarate in astrocytes involve glutathione and haem oxygenase-1. ASN Neuro 3(2). CrossRef Medline

Linker RA, Lee DH, Ryan S, van Dam AM, Conrad R, Bista P, Zeng W, Hronowsky X, Buko A, Chollate S, Ellrichmann G, Brück W, Dawson K, Goelz S, Wiese S, Scannevin RH, Lukashev M, Gold R (2011) Fumaric acid esters exert neuroprotective effects in neuroinflammation via activation of the Nrf2 antioxidant pathway. Brain 134:678-692. CrossRef Medline

Litjens NH, Burggraaf J, van Strijen E, van Gulpen C, Mattie H, Schoemaker RC, van Dissel JT, Thio HB, Nibbering PH (2004) Pharmacokinetics of oral fumarates in healthy subjects. Br J Clin Pharmacol 58:429-432. CrossRef Medline

Liu YS, Li HS, Qi DF, Zhang J, Jiang XC, Shi K, Zhang XJ, Zhang XH (2014) Zinc protoporphyrin IX enhances chemotherapeutic response of hepatoma cells to cisplatin. World J Gastroenterol 20:8572-8582. CrossRef Medline

Liu Y, Qiu J, Wang Z, You W, Wu L, Ji C, Chen G (2015) Dimethylfumarate alleviates early brain injury and secondary cognitive deficits after experimental subarachnoid hemorrhage via activation of Keap1-Nrf2-ARE system. J Neurosurg 123:915-923. CrossRef Medline

Livak KJ, Schmittgen TD (2001) Analysis of relative gene expression data using real-time quantitative PCR and the 2(-Delta Delta C(T)) method. Methods 25:402-408. CrossRef Medline

Olanow CW, Kieburtz K, Schapira AH (2008) Why have we failed to achieve neuroprotection in Parkinson's disease? Ann Neurol 64 (Suppl 2): S101-S110. CrossRef Medline

Otterbein LE, Soares MP, Yamashita K, Bach FH (2003) Heme oxygenase-1: unleashing the protective properties of heme. Trends Immunol 24: 449-455. CrossRef Medline

Rostami-Yazdi M, Clement B, Schmidt TJ, Schinor D, Mrowietz U (2009) Detection of metabolites of fumaric acid esters in human urine: implications for their mode of action. J Invest Dermatol 129:231-234. CrossRef Medline

Ruggieri S, Tortorella C, Gasperini C (2014) Pharmacology and clinical efficacy of dimethyl fumarate (BG-12) for treatment of relapsing-remitting multiple sclerosis. Ther Clin Risk Manag 10:229-239. CrossRef Medline Savitt JM, Dawson VL, Dawson TM (2006) Diagnosis and treatment of Par- kinson disease: molecules to medicine. J Clin Invest 116:1744-1754. CrossRef Medline

Scannevin RH, Chollate S, Jung MY, Shackett M, Patel H, Bista P, Zeng W, Ryan S, Yamamoto M, Lukashev M, Rhodes KJ (2012) Fumarates promote cytoprotection of central nervous system cells against oxidative stress via the nuclear factor (erythroid-derived 2)-like 2 pathway. J Pharmacol Exp Ther 341:274-284. CrossRef Medline

Schmidt TJ, Ak M, Mrowietz U (2007) Reactivity of dimethyl fumarate and methylhydrogen fumarate towards glutathione and N-acetyl-L-cysteinepreparation of S-substituted thiosuccinic acid esters. Bioorg Med Chem 15:333-342. CrossRef Medline

Sheikh SI, Nestorov I, Russell H, O'Gorman J, Huang R, Milne GL, Scannevin RH, Novas M, Dawson KT (2013) Tolerability and pharmacokinetics of delayed-release dimethyl fumarate administered with and without aspirin in healthy volunteers. Clin Ther 35:1582-1594.e9. CrossRef Medline

Smirnova NA, Haskew-Layton RE, Basso M, Hushpulian DM, Payappilly JB, Speer RE, Ahn YH, Rakhman I, Cole PA, Pinto JT, Ratan RR, Gazaryan IG (2011) Development of Neh2-luciferase reporter and its application for high throughput screening and real-time monitoring of Nrf2 activators. Chem Biol 18:752-765. CrossRef Medline

Spencer CM, Crabtree-Hartman EC, Lehmann-Horn K, Cree BA, Zamvil SS (2015) Reduction of CD8(+) T lymphocytes in multiple sclerosis patients treated with dimethyl fumarate. Neurol Neuroimmunol Neuroinflamm 2:e76. CrossRef Medline

Taylor JM, Main BS, Crack PJ (2013) Neuroinflammation and oxidative stress: co-conspirators in the pathology of Parkinson's disease. Neurochem Int 62:803-819. CrossRef Medline

Thomas B, von Coelln R, Mandir AS, Trinkaus DB, Farah MH, Leong Lim K, Calingasan NY, Flint Beal M, Dawson VL, Dawson TM (2007) MPTP and DSP-4 susceptibility of substantia nigra and locus coeruleus catecholaminergic neurons in mice is independent of parkin activity. Neurobiol Dis 26:312-322. CrossRef Medline

Thomas B, Banerjee R, Starkova NN, Zhang SF, Calingasan NY, Yang L, Wille E, Lorenzo BJ, Ho DJ, Beal MF, Starkov A (2012) Mitochondrial permeability transition pore component cyclophilin D distinguishes nigrostriatal dopaminergic death paradigms in the MPTP mouse model of Parkinson's disease. Antioxid Redox Signal 16:855-868. CrossRef Medline

Turley AE, Zagorski JW, Rockwell CE (2015) The Nrf2 activator tBHQ inhibits $\mathrm{T}$ cell activation of primary human CD4 T cells. Cytokine 71:289-295. CrossRef Medline

van Kester MS, Bouwes Bavinck JN, Quint KD (2015) PML in patients treated with dimethyl fumarate. N Engl J Med 373:583-584. CrossRef Medline

von Stedingk EM, Pavlov PF, Grinkevich VA, Glaser E (1997) Mitochondrial protein import: modification of sulfhydryl groups of the inner mitochondrial membrane import machinery in Solanum tuberosum inhibits protein import. Plant Mol Biol 35:809-820. CrossRef Medline

Xie X, Zhao Y, Ma CY, Xu XM, Zhang YQ, Wang CG, Jin J, Shen X, Gao JL, Li N, Sun ZJ, Dong DL (2015) Dimethyl fumarate induces necroptosis in colon cancer cells through GSH depletion/ROS increase/MAPKs activation pathway. Br J Pharmacol 172:3929-3943. CrossRef Medline

Yagi T, Hatefi Y (1987) Thiols in oxidative phosphorylation: thiols in the F0 of ATP synthase essential for ATPase activity. Arch Biochem Biophys 254:102-109. CrossRef Medline

Yang L, Calingasan NY, Thomas B, Chaturvedi RK, Kiaei M, Wille EJ, Liby KT, Williams C, Royce D, Risingsong R, Musiek ES, Morrow JD, Sporn M, Beal MF (2009) Neuroprotective effects of the triterpenoid, CDDO methyl amide, a potent inducer of Nrf2-mediated transcription. PLoS One 4:e5757. CrossRef Medline

Yin F, Dumont M, Banerjee R, Ma Y, Li H, Lin MT, Beal MF, Nathan C, Thomas B, Ding A (2010) Behavioral deficits and progressive neuropathology in progranulin-deficient mice: a mouse model of frontotemporal dementia. FASEB J 24:4639-4647. CrossRef Medline

Zhang M, An C, Gao Y, Leak RK, Chen J, Zhang F (2013) Emerging roles of Nrf2 and phase II antioxidant enzymes in neuroprotection. Prog Neurobiol 100:30-47. CrossRef Medline 